\title{
Obesity: the metabolic disease, advances on drug discovery and natural product research
}

\author{
Mafalda Castro ${ }^{\mathrm{a}}$, Marco Preto ${ }^{\mathrm{a}}$, Vitor Vasconcelos ${ }^{\mathrm{a}, \mathrm{b}}$ and $*$ Ralph Urbatzka ${ }^{\mathrm{a}}$ \\ (The author will be required to provide their full names, the institutional affiliations and the location, with an asterisk in front of the name \\ of the principal/corresponding author).
}

${ }^{a}$ Interdisciplinary Centre of Marine and Environmental Research (CIIMAR/CIMAR), University of Porto,
Porto, Portugal; ${ }^{b}$ Department of Biology, Faculty of Sciences, University of Porto, Porto, Portugal

\begin{abstract}
Obesity is a global health threat. OECD reported that more than half (52\%) of the adult population in the European Union is overweight or obese. Obesity and obesity-related co-morbidities have deep negative effects on morbidity, mortality, professional and personal quality of life. Health-care costs represent a negative impact of this disease, with an associated economic cost of 100 billion US\$ per year in the United States. The most prescribed drugs for obesity treatment worldwide are orlistat, and phentermine/topiramate extended release, while the major prescribed drug for the same disease in the US are exenatide and dapagliflozin. The so far developed drugs, targeting weight loss, have a long history of malignant secondary effects. There is still a lack of efficient and safe drugs to treat obesity and related metabolic complications since in many cases cure cannot be reached by bariatric surgery or healthy lifestyle habits. Terrestrial and aquatic organisms are a promising source of valuable, bioactive compounds, often with interest for human health. Some of the natural compounds or organisms have been used for centuries by humans as traditional medicine foods. In this review, we give insights into the adipose tissue function and development, and the progress in traditional anti-obesity pharmacotherapy. A major focus is to highlight the state of the art of natural compounds with anti-obesity properties and their potential as candidates for drug development; an overview is given about natural compounds derived from different marine animal sources, cyanobacteria, marine phytoplankton, fungus or plants.
\end{abstract}

Keywords: obesity; metabolic disease; diabetes; natural products; pharmacotherapy; anti-obesity; secondary metabolites

\section{INTRODUCTION}

Obesity is a global health hazard associated with health problems such as hypertension, high cholesterol, diabetes, cardiovascular diseases, sleep apnea, respiratory problems (asthma), musculoskeletal diseases (arthritis) and some forms of cancer [1]. In the last 20 years, the percentage of obesity has nearly doubled in many European countries. The highest rates of obese adults are found in Mexico, followed by New Zealand and the United States, representing more than one third of the population, whereas in Asian countries the rates are between 2 and 4\% (OECD, 2014). Healthy lifestyle promotion and lifestyle changes are preventive and straightforward. However, a large percentage of the world's population may not be able to depend on this methodology alone, when treating obesity.

Obesity, as a metabolic failure causing disease, has had some compelling evidence suggesting more morbidity than smoking or alcoholism and pointing it as a leading cause of preventable death in the United States [2]. Diet, exercise, drug therapy, bariatric surgery or combinations of these are the current used methods to treat and prevent obesity [3]. Changes in diet and exercise can be an unreliable method,

*Address correspondence to this author at the Interdisciplinary Centre of Marine and Environmental Research (CIIMAR/CIMAR), Rua dos Bragas 289, 4050-123 Porto, Portugal, Tel/Fax: p: +351 223401 818, +351 223 390 608; E-mail: rurbatzka@ciimar.up.pt ultimately resulting in regain of lost weight.

Bariatric surgery, used for patients with morbid obesity (Body Mass Index $\geq 40$ ) is an invasive method with history of after-surgery complications. Bariatric surgery has been proven to be efficient in sustained weight loss, glycemic control and improved blood pressure and lipid profile. Although a big effort has been done to reduce surgical risk and recovery times, this technique still is a very invasive and expensive method with serious metabolic complications [4].

Throughout history, pharmaceutical companies have been unable to develop safe and effective anti-obesity drugs, with numerous cases of drugs with several hazardous side effects, as for the intracranial bleeding and strokes associated caused by phenylpropanolamine [5] and heart attacks, hypertension and sudden deaths on people under dietary supplements containing ephedra alkaloids [6]. Despite the increasing need, the only anti-obesity drugs approved by both the food and drug administration (FDA) and the European Medicines Agency (EMA) are orlistat, phentermine/topiramate extended release, exenatide and dapagliflozin. Orlistat is a powerful inhibitor of lipases from both the stomach and intestines, derived from lipstatin, a natural product of the bacterium Streptomyces toxytricini [7]. Preventing the absorption of fat from the diet, it reduces the caloric intake, which combined with lifestyle changes has been still proven to be the most effective, resulting typically 
in a weight reduction of 5-10\% of body weight [8]. Phentermine/topiramate extended release acts by noradrenergic and GABAergic activation, leading to appetite suppression. Exenatide is a medication for the treatment of type 2 diabetes mellitus (T2DM), acting by increasing insulin sensitivity. Dapagliflozin is a synthetic analog of phlorizin, responsible for the inhibition of glucose reuptake in nephron. New approaches for the development of new anti-obesity drugs are needed based on a better understanding of molecular and metabolic pathways on lipogenesis.

Adipocytes, playing an important role as regulators of whole-body metabolism and homeostasis, originate from precursor cells [9]. Obesity, at the cellular level, is manifested as increase in the adipocyte cell size (hypertrophy) and cell number (hyperplasia) increase and both of these processes are largely dependent on the regulation of adipocyte differentiation [10].

\section{The adipose tissue}

\subsection{Dynamics of the adipose tissue}

The perception of the adipose tissue changed markedly from simple fat storing cells to hormone-secreting cells with impact on the whole-body metabolism, energy metabolism in distant tissues, and sensitivity regulation towards insulin signaling. Nowadays, it is recognized that the adipose tissue has crucial roles in thermogenesis, lactation, immune responses, endocrine regulation and energy provision. The tissue is composed of many cell types, as endothelial cells, hematocytes, pericytes, pre-adipocytes, macrophages and other immune cells [11]. However, in mammals, the adipose tissue is mainly constituted by two morphologically and physiologically very different types of cells: white adipocytes are cells with a single cytoplasmic lipid droplet and a squeezed nucleus, whereas brown adipocytes are polygonal cells with a round nucleus, several cytoplasmic lipid droplets and numerous large mitochondria. These two types of cells also differ in their distribution in the human body: white adipocytes are mostly found in subcutaneous (under the skin) and visceral depots (near internal organs), while brown adipocytes are found in visceral depots and near the aorta [12]. Brown adipose tissue (BAT) is exclusive to mammals and recognized as an evolutionary advantage, since it is specialized in body temperature maintenance, allowing mammals to survive during cold stress. This function is mediated by uncoupling protein-1 (UCP1) in the mitochondria [13], an exclusive protein of the BAT. Scientists also consider a third type of adipose tissue, which is under intense investigation, but its origin and function remaining unclear. Beige adipocytes are regions in the white adipose tissue containing brown or brown-like adipocytes [14]. This intermediate type of adipose tissue is thought to have different origins than the brown adipose tissue : they originate from white adipocytes with the expression of positive regulatory domain containing 16 (PRDM16), a transcriptional modulator required for thermogenesis [14], when under $\beta 3$-adrenergic stimulation, chronic activation of Peroxisome proliferator-activated receptor gamma (PPAR $\gamma$ ) or adaptation to cold response [15]. It was previously known that the adipose tissue responds to physiological and environmental stimuli, due to its high density in nerve fibers in contact with adipocytes, allowing it to interfere with the nervous system [16]. The appearance of brown adipocytes itself (browning phenomenon) has been observed after adrenergic stimulus or cold exposure, derived from a direct transformation of white adipocytes into brown adipocytes (white-to-brown transdifferentiation) $[12,17]$. This shows the inherent plasticity of this important tissue and has a big impact on understanding obesity and its prevention, since it is accepted that individuals with more brown adipose tissue are more resistant to obesity and T2DM [18].

A special kind of adipocyte differentiation occurs during pregnancy and lactation. In female mice subcutaneous depots can transform into milk-secreting glands by adipoepithelial transdifferentiation [19]. This enhances the plasticity of this complex organ: the ability to reversibly differentiate into morphological and physiological different cells. Adipocytes have also been known to possess endocrine functions, secreting important hormones and adipokines which are considered to be important regulators of the whole-body metabolism. Leptin was the first characterized hormone to be secreted by the adipose tissue [20]. This hormone is produced by the obese (ob) gene and regulates energy homeostasis through binding to the leptin receptor (LEPR) in the hypothalamus. Leptin regulates appetite and food uptake, further directed by anorexigenic (appetite suppressing) or orexigenic (appetite stimulating) neuropeptides. On the one hand, when the adipose tissue decreases in mass, leptin levels decline and neuropeptide Y levels rise, leading to higher food intake [21]. Weight gain increases the adipokine levels, resulting in decreased food intake. Through this feedback mechanism, leptin regulates adipose tissue mass. Pivotal roles of this hormone have been described also for the regulation of the reproductive, cognitive or immune system, and related autoimmune disorders, bone metabolism or hematopoiesis. Other hormones produced by adipocytes are for example adiponectin or resistin. Adiponectin acts on the regulation of many physiological processes as glucose and lipid metabolism [22]. Resistin, mainly produced by monocytes and macrophages within the adipose tissue, is involved in the pathogenesis of insulin resistance [23,24].

The adipose tissue is crucial for a well-functioning metabolism and characterized as a complex organ due to its inherent plasticity, its ability to increase or decrease the number of constituent cells, and its transdifferentiation potential.

\subsection{The Metabolic Disease}

Obesity is a complex metabolic disorder, characterized by the accumulation of fat in different body regions, due to a positive energy balance. Metabolic complications of obesity are T2DM, cardiovascular disease or cancer.

Interaction between genetic, behavioural and environmental factors has been proven to lead to obesity. Excessive nutrient intake, lack of exercise and genetic susceptibility are established as the main causes of obesity [25]. However, some endocrine disrupting chemicals, such as phthalates, bisphenol A and alkylphenols, are suspected to contribute to a high prevalence of obesity or developing obesity [26, 27]. Interestingly, associations exist between gut microbiota composition and obesity. The mechanisms through which these microbes exert their anti-obesity effects are still unclear. However, links have been made between 
two distinct phyla of bacteria: the phylum Firmicutes is associated with obesity, whereas the phylum Bacteroidetes is associated with weight loss. Furthermore, the transplant of microbiota from obese or western diet-fed mice to lean mice resulted in weight gain [28].

At the cellular level, obesity is manifested as increase of the cell size (hypertrophy) or the cell number (hyperplasia) and both processes are largely dependent on the regulation of adipocyte differentiation [10]. Adipocytes do not only store lipids, but, as mentioned before, also control the sensitivity towards insulin signalling and secrete hormones with long range effects involved in energy metabolism in distant tissues. Today, adipocytes are recognized as critical regulators of the whole-body metabolism [29].

The adipocyte plasticity is critical for insulin sensitivity and overall metabolic health. Consequently, disturbances of adipocyte regulation are the origin of some metabolic diseases such as T2DM. However, T2DM and obesity are not exclusively correlated. Some obese people are diabetic, but a big percentage of the population is characterized as non-diabetic obese people, identified as metabolically healthy obese [30]. Metabolically healthy obese people have well-functioning adipocytes and thus lower mortality risks. The correlation commonly seen between obesity and T2DM is based on insulin resistance, characterized by cells that become resistant to the effects of insulin leading to glucose uptake. Physiological transformations of the adipose tissue, in particular adipocyte hypertrophy, as a result of obesity, adipocyte death and adipocyte stress result in increasing adipocyte remnants that need absorption by specialized cells as macrophages. Chronic deposition of these remnants causes therefore the chronic deposition of macrophages in the adipose tissue, which finally causes inflammation [31]. The higher presence of macrophages lead to higher content in cytokines in the obese adipose tissue; Furthermore, circulation of free fatty acids (FFAs) and FFAs depots in non-adipose tissues, as muscles, can also contribute to insulin resistance through the release of chemoattractant proteins [32]. Cytokines as tumour necrosis factor- $\alpha$ (TNF $\alpha$ ), interleukin-6 (IL-6), interleukin-1 $\alpha$ (IL-1 $\alpha$ ) and interferon gamma (IFN $\gamma$ ) are potent inhibitors of cellular differentiation of adipocytes and lead to insulin resistance in mature adipocytes [33]. Cytokines, and in particular $\mathrm{TNF} \alpha$, are potent inhibitors of adipocyte differentiation via the PPAR $\gamma$ receptor, and lead to decreased triglyceride deposition and higher fatty acid level. Resulting consequences are ectopic lipid deposition and impaired glucose transport, which ultimately cause insulin resistance in mature adipocytes or muscle cells. Significantly reduced insulin receptor substrate 1 (IRS-1) and protein kinase B (PKB) phosphorylation levels were observed in adipocytes from patients with T2DM. Concomitantly, high levels of pro-inflammatory cytokines (IL-6, nuclear factor kappalight-chain-enhancer of activated $\mathrm{B}$ cells $(\mathrm{NF}-\kappa \mathrm{B})$ ) were detected [34]. Nitric oxide released by macrophages may as well be responsible for increasing the susceptibility of adipocytes to gain insulin resistance [35].

Metabolic complications like T2DM may also be a consequence of other stimuli resulting from the expanding adipose tissue microenvironment. Hypoxia, due to the rapid expansion, leads to higher levels of fatty acids and products of cell death, which causes the migration of innate and adaptive immune cells, and finally inflammation of the adipose tissue [36]. Hence, inflammatory conditions due to adipose tissue expansion is the underlying cause to T2DM development and further consequences [37, 38].

Obesity has further been linked with a series of cancers. Hormone dependent cancers as postmenopausal breast and ovarian cancers can be more frequent with high body weight and high fat index, since adipokines increase with adipose tissue mass and present pro-inflammatory activities. Leptin exerts its activity through the leptin receptor, and inactivation of this receptor inhibits the proliferation and viability of human breast cancer cell lines [39]. The association between obesity and cancer was also demonstrated in adipocytes in vitro, glucose and fatty acids modulated the secretion of growth factor and cytokine, which in turn induced the proliferation of cancer cells [40].

Even though there is little information about behavioural and obesity profiles, certain neurotransmitters are linked with this disease. Neurotransmitters as dopamine and norepinephrine have been found to modulate appetite and food intake. The relationship between the stimuli to higher or lowered food intake is thought to be the underlying mechanism. Dopamine has been particularly studied, and modulates food intake altering the food reward via the mesolimbic circuitry of the brain [41]. Blockers of dopamine D2 receptors result in increases of appetite and weight gain [42], while drugs that increase brain dopamine concentration present anorexigenic (appetite supressing) properties [43, 44]. Food intake can be mediated as well by the endogenous levels of norepinephrine. Increases in norepinephrine will lead to lowered food intake, [45] and serotonin and norepinephrine reuptake inhibitors induce satiety and effectively reduce the accumulation of abdominal fat [46]. High intake of calories increases noradrenergic turnover in peripheral tissues, causing elevated norepinephrine plasma level. The availability of norepinephrine transporter is decreased in the thalamus of obese individuals, supporting a link between noradrenergic dysfunction and norepinephrine levels in obesity [47].

Moreover, physical activity is also an important regulator of obesity via alteration of neurotransmitter level or inflammatory cytokines. Decreases in bodily activity (e.g. sedentary lifestyle) can lead to lowered noradrenergic levels, causing weight gain. Cardiorespiratory fitness was demonstrated to help preventing by decreasing inflammation and by protecting against adrenergic desensitization. Inflammatory cytokines were described to desensitize $\beta$ adrenergic receptors to their ligands by elevating $G$ proteincoupled receptor kinase-2 (GRK-2) [48]. Several studies that reported weight loss, either through hypocaloric diet, exercise or liposuction, observed the reduction of the levels of circulating cytokines, as IL-6 and TNF- $\alpha$, due to the decrease in adipose tissue mass [49, 50]. Also, neurohormones as catecholamines, adenosine and dopamine, which are higher during exercise, have the ability to inhibit pro-inflammatory functions of macrophages [51, 52].

\subsection{Adipose tissue development}

White adipose tissue is the main energy reserve in higher eukaryotes, in contrast to brown adipose tissue which dissipates energy through thermogenesis. White adipocytes are crucial to energy mobilization during energy deprivation. 
When the energy intake is greater than the energy outflow, the adipose tissue expands. The growth of adipose tissue can result from an increase in adipocyte size (hypertrophy), adipocyte number (hyperplasia) or both [10]. Hypertrophy and hyperplasia are mainly determined by the number of differentiated adipocytes since the same content of lipids can either be stored in in few, big or in many, small adipocytes. The differentiation and proliferation of pre-adipocytes are the main factors determining the adipose tissue mass.

The adipose tissue derives from pluripotent mesenchymal stem cells. These cells have the ability to undergo differentiation into adipocytes, myocytes, chondrocytes and osteocytes [53] depending on the stimuli received. Differentiation into adipocytes requires passage through a pre-adipocyte stage, which, under appropriate conditions, will originate mature adipocytes. Pre-adipocyte proliferation occurs through clonal expansion and represents the initial steps towards adipogenesis, determining the number of mature adipocytes throughout adulthood [54]. During proliferation, some genes are significantly up-regulated as cyclin B2, cyclin D1 and cyclin E1, proliferating cell nuclear antigen (PCNA) and the insulin-like growth factor-1 (IGF-1) that is a potent activator of the protein kinase B (Akt) pathway that leads to cell growth and proliferation.

Adipocyte differentiation is induced by agents such as insulin or adrenergic mediators (epinephrine, cyclic adenosine monophosphate (cAMP)). Insulin acts through the activation of the IGF-R signaling pathway, which alters the expression of the sterol regulatory element-binding protein-1 (SREBP-1) and results in the stimulation of glucose transporter type 4 (GLUT-4) - mediated glucose uptake and lipid synthesis. Increases of the cAMP, lead to phosphorylation of the cAMP response element-binding protein (CREB) that activates the expression of endogenous CCAAT/enhancer binding protein- $\alpha$ (C/EBP- $\alpha)$, a transcription factor crucial for adipocyte differentiation and lipid synthesis and accumulation. PPAR $\gamma$ is an important nuclear receptor with an active role in the regulation of adipogenesis, stimulating the expression of target genes involved in adipocyte differentiation and increased lipid storage [55]. During differentiation, pre-adipocytes lose their fibroblastic morphology, start to accumulate triglycerides in their characteristic lipid droplets, and acquire the appearance and metabolic features of mature adipocytes [56].

Model cell culture systems have been vital in obesity studies. Pre-adipocyte cell lines, as 3T3-F442A and 3T3-L1, were first established as a valid model system in the laboratory of Green [56]. Both were originally developed by clonal expansion from murine Swiss 3T3 embryo cells and became a standard for studying pre-adipocyte differentiation, due to its efficiency to differentiate from fibroblasts to adipocytes.

To trigger the cascade of cell differentiation, protocols have been developed for effective in vitro differentiation. At the point of growth arrest, cells can be exposed to a cocktail composed of differentiation inducing agents. For the complete differentiation of the cell line 3T3-L1, an appropriate and effective cocktail has been established containing insulin, dexamethasone, and 3-isobutyl-1methylxanthine (IBMX) [57]. Insulin acts through the activation of the IGF-R signaling pathway; dexamethasone acts through the glucocorticoid signaling pathway; IBMX is an agent used to elevate the cellular cAMP.

\section{Anti-obesity Pharmacotherapy}

As outlined before, obesity is a complex metabolic disease with no single cause or cure. Over the years many drugs have been proposed to treat or prevent obesity. During the long history of anti-obesity pharmacotherapy many drugs displayed a wide range of dangerous side-effects.

Anti-obesity drug development should focus on using a safe and effective drug regimen with a proper combination of improved diet and exercise, in order to attain a reasonable and sustainable reduction of body weight. For a drug to be approved in the treatment of obesity by the FDA it requires that the difference in mean weight loss between the drug and the placebo groups is at least 5\% for at least 1 year and statistically significant, and that the proportion of subjects who lose at least $5 \%$ of baseline body weight in the active product group is at least $35 \%$ and is approximately the double of the proportion in the placebo-treated group [58]. Drug development for the treatment and prevention of obesity should focus on long-term treatments, hence ensuring long term efficacy and safety. Obesity, like hypertension, requires long-term control and treatment. FDA and EMA approved drugs still require the thoroughly analysis by the clinician of the benefits and risks' balance.

As of December 2013, four drugs have been approved by both the FDA and the EMA for chronic weight management and obesity complications: orlistat (Alli®, GlaxoSmithKline; Xenical ${ }^{\circledR}$, Roche), phentermine/topiramate extended release (Qsymia ${ }^{\circledR}$, Vivus), exenatide (Byetta ${ }^{\circledR}$, Bydureon ${ }^{\circledR}$, BristolMyers Squibb) and dapagliflozin (Farxiga ${ }^{\circledR}$, Forxiga ${ }^{\circledR}$, Bristol-Myers Squibb and AstraZeneca)). The FDA has also approved lorcaserin (Belviq ${ }^{\circledR}$, Arena Pharmaceuticals), pramlintide (Symlin ${ }^{\circledR}, \quad$ Amylin Pharmaceuticals) and phentermine (Qnexa®), Vivus), for the long-term treatment of obesity in 2012. Phentermine and lorcaserin are two appetite suppressants used for the treatment of obesity through noradrenergic activation. Pramlintide is the synthetic analogue of amylin that promotes satiety and inhibits the secretion of glucagon. However, EMA has rejected these drugs due to limited efficacy, carcinogenic and teratogenic potential, cardiovascular events and cognitive impairment, considering that their side-effects would not outweigh their benefits. In the following, we present some of the short-term and long-term drugs approved by the FDA/EMA and some alternative medications for the treatment and prevention of obesity. The drugs usually applied in obesity treatment can be mainly divided in three groups: drugs suppressing appetite, drugs increasing insulin sensitivity, drugs targeting sodium/glucose co-transporters and drugs decreasing lipid absorption.

\subsection{Drugs suppressing appetite}

Noradrenergic drugs, acting by suppressing appetite, are FDA-approved for the short-term (less than 12 weeks) treatment of obesity. Phentermine is the most widely prescribed obesity medication in the United States [59]. Phentermine is used as a short-term treatment for obesity that acts by stimulating the anorexic signalling in the hypothalamus or the dopamine receptor in the hippocampus. Diethylpropion is another noradrenergic drug for the shortterm treatment of obesity with a similar adverse effect and 
weight loss profile to phentermine but less commonly prescribed [59]. Common adverse effects of this group of drugs are listed in Table 1. Lorcaserin, a highly selective monoaminergic neurotransmitter 5-hydroxytryptamine $2 \mathrm{C}$ receptor agonist, acts by appetite suppression and is used for the long-term treatment of obesity. This drug was FDA approved in 2012, after the results of clinical trials demonstrated decreases in blood pressure, total and low density lipoprotein (LDL)-cholesterol and triglycerides [60]. Another approach on treating obesity is combination therapy. Phentermine/topiramate-ER is a noradrenergic and GABAreceptor activator, kainate/AMPA glutamate receptor inhibitor, ultimately causing appetite suppression. Other medications had a potential for obesity treatment or prevention. Fluoxetine, a serotonin selective reuptake inhibitor used for the treatment of depression, was found to promote weight loss up to six months, but not in a long-term manner [61].

Zonisamide, an antiepileptic medication, was also seen to induce weight loss. It is known to modulate GABAergic and glutamatergic neurotransmission and has anorexia as a lateral effect. However, its mechanism of action is yet to be described. In combination with bupropion, a weak norepinephrine-dopamine reuptake inhibitor, Empatic ${ }^{\circledR}$ (Orexigen Therapeutics) is in phase II trials [62].

\subsection{Drugs increasing insulin sensitivity}

Another route for anti-obesity drug development is for insulin sensitivity improvement, since insulin resistance has been largely described in obese individuals. Metformin is a short-term treatment for individuals with T2DM. The drug produced small sustained weight losses, primarily by suppressing glucose production by the liver and decreasing episodes of hyperglycaemia [63]. Two developed drugs are described to act on glycaemic modulation that ultimately leads to recovering insulin sensitivity and to improve the metabolic complications. Pramlintide, a synthetic analogue of human amylin, is subscribed for patients with type I and II diabetes [64, 65]. Amylin is a hormone that decelerates gastric emptying and promotes satiety via hypothalamic receptors, by inhibiting the secretion of glucagon. Its analogue was seen to promote weight loss in a similar way. Exenatide is an analogue of the hormone glucagon-like peptide-1, an antihyperglycaemic hormone, which also targets on gastric emptying delay and suppression of appetite [64]. As Byetta ${ }^{\circledR}$, it was approved by the FDA in 2005 and the EMA in 2006 for the long term treatment of T2DM. Although this group of drugs improve weight loss, the blocking of gluconeogenesis in the liver can lead to adverse effects as muscle pain due to increased lactic acidosis (Table 1).

\subsection{Drugs inhibiting sodium/glucose co-transporters}

Another class of compounds are sodium/glucose cotransporter 2 (SGLT2) inhibitors. Dapagliflozin (Forxiga ${ }^{\circledR}$ ) is a synthetic analogue of the natural compound phlorizin, which competes with glucose in the proximal tubule of the nephron, thereby decreasing glucose reuptake and the levels of glucose in the blood stream [66, 67]. This compound, approved in 2014 by the FDA, has shown beneficial effects in weight reduction and the improvement of insulin sensitivity. Other analogues of these natural compounds are to be launched and to be developed.

\subsection{Drugs decreasing lipid absorption}

In the group lipid absorption decreasing drugs, the main anti-obesity drug is presented. Orlistat is used for the longterm treatment of obesity, approved by the FDA early in 1999 and the EMA in 2006. Orlistat effectively inhibits pancreatic and gastric lipases, and stops the breakdown of dietary lipids into fatty acids and monoglycerides. As a result, approximately $32 \%$ of the ingested fat is excreted compared to 5\% during administration of placebo [68]. Even though orlistat has been occasionally associated with acute kidney injury, which can occur due to disturbances in fat absorption, it is vital to carbohydrate metabolism and has been widely and safely used as a consensual anti-obesity drug.

\subsection{Future approaches}

The approach on drug discovery can focus on peripheral or central targets, although a combined approach can lead to more efficient strategies [69]. Even though European Organizations seem skeptical towards appetite suppressants as lorcaserin [70] due to its lateral effects, many submissions for drug approval are being delivered as a form of combination therapy.

It was believed that inhibitors of adipogenesis could be a potential anti-obesity therapy. However, it has been seen in mice and humans that this could lead to a poor metabolic health state, since limiting adipocyte expansion is associated with insulin resistance, leading to T2DM [71]. Danforth (2000) proposed that when adipose tissue stops accommodating excess calorie intake due to expansion or differentiation impairment can result in lipodystrophy; this process decreases leptin levels and adipose tissue displays degenerative conditions. Later on, Dubois and co-workers [72] found evidence that subjects with T2DM larger adipocytes when compared with adipocytes of non-diabetic individuals (adipocyte hypertrophy), while having the same number of adipocytes, and that insulin sensitivity is inversely related to fat cell size. Recruitment of pre-adipocytes in adipose tissue is able to prevent obesity-related metabolic complications, rather than restricting adipogenesis [73]. In this context, the stimulation of adipocyte hyperplasia could be beneficial to accommodate the surplus energy and to reduce the obesity associated co-morbidities as T2DM or cardiac disease.

Some published papers described activities through UCP modulation, an important protein involved in thermogenesis and a possible therapeutic target for obesity. Brown adipose tissue in mammals, specialized in energy dissipation for thermogenesis, has also been considered as a target for antiobesity treatment. It has been established that the noradrenergic system is also able to activate BAT, through increase of catecholamines or $\beta$-adrenergic receptors activation [74].

As described before, the availability of norepinephrine at noradrenergic synapses can be regulated by motivated behaviors that might be important contributions to the development of obesity. Therefore, the norepinephrine transporter in the cortical and subcortical brain regions may also be a therapeutic target for drug development as stimulants and antidepressants. Since dopamine has also been seen differentially present in obese and non-obese individuals, drug development focusing on the modulation of 
dopamine levels and reward circuits could be a beneficial strategy.

Recently, a new approach on development of anti-obesity drug has been proposed, targeting the purinergic system that might also be involved in BAT activation. Adenosine, as an endogenous ligand of a class of purinergic receptors, is able to effectively activate human and murine brown adipocytes [75]. The treatment with adenosine $A_{2 A}$ agonists results in higher glucose tolerance and less body fat. A higher gene expression of $\mathrm{A}_{2 \mathrm{~A}}$ receptors leads to decreased adipocyte hypertrophy, reduced expression of inflammatory cytokines and increased expression of BAT marker [75]. Thus, the socalled browning of the adipose tissue might be a new approach for developing innovative obesity therapies.

\section{Approved natural compound for disease treatment}

The potential of natural compounds on drug development has been widely explored and proven to be a reliable and fruitful source. Natural compounds from organisms as primary metabolites (steroids, nucleosides, etc.), vitamins, hormones, protein fragments, herbal mixtures and polyamines fall into the category of natural product drugs, even if they are synthetically produced, whereas compounds inspired from a natural product template, but synthetically derived are considered natural product derived drugs.

Semi-synthetic drugs of natural origin had a natural compound as a template, and currently marketed with some modifications and synthetically produced. Synthetic drugs don't share similarities with known natural compounds and are therefore synthetically derived. In 2010, around $10 \%$ of the drugs on the market were unaltered natural products, $29 \%$ derived from natural products, known as semisynthetic, and the rest $(61 \%)$ was composed with drugs of synthetic origin [76]. The unmodified natural products tended to decrease due to the prevalent introduction of many new synthetic drugs [77]. Between 2000 and 2013, 25\% (14 out of the 56) approved drugs with natural origin were unaltered natural products, while the majority were semisynthetic natural products [78]. Between 2008 and 2013, a total of 25 natural product and natural product derived drugs were approved, representing $18 \%$ of the $100 \mathrm{NP}$ and NPderived compounds reviewed in [78]. These numbers underline the importance of natural product discovery. Important therapeutic areas for new natural products and semi-synthetic natural compounds are oncology and infectious diseases, which make up to $64 \%$ of the natural drug targets.

The first two marine-derived natural products that have been developed into drug substances were cytarabine (Cytosar-U®, Depocyt ${ }^{\circledR}$ ), a synthetic pyrimidine nucleoside last approved by the EMA in 2001 for the treatment of cancer, and vidarabine, a synthetic purine nucleoside with antiviral properties, both developed from natural compounds from the Carribbean sponge Tethya crypta [79]. About 6 years later, ziconotide (Prialt $\AA$ ), was approved for the treatment of moderate to severe pain. Ziconotide is the synthetic formula of a 25 -amino acid peptide, originally isolated from the venom of the marine snail Conus magus [80]. Trabectedin (Yondelis ${ }^{\circledR}$ ) is a marine-derived product, approved by the EMA in 2003 for the treatment of soft tissue sarcoma and ovarian carcinoma, isolated from the tunicate Ecteinascidia turbinate found in the Caribbean and
Mediterranean seas [81]. In 2010, a natural product derived drug was approved by the FDA and EMA for the treatment of metastatic breast cancer: halichondrin $\mathrm{B}$, a polyether isolated from the marine sponge Halichondria okadai [82].

Natural product discovery for the treatment of cardiovascular and metabolic diseases has also a high demand of drug development. This group includes the SGLT2 inhibitors described before (Section 3), derived from the natural product phlorizin, a polyphenol. Synthetic compounds derived from phlorizin were shown to be more effective and selective, mainly due to the reduced degradation by glucosidase enzymes and increased intestinal absorption. Derived drugs developed are dapagliflozin and canagliflozin (Invokana ${ }^{\circledR}$, Janssen Pharmaceuticals, Inc), approved by the EMA. Many other analogues are currently in phase III and phase II clinical trials.

Another compound for patients with classical Hodgkin's lymphoma, peripheral T-cell lymphoma, diffuse large B-cell lymphoma or systemic anaplastic large cell lymphoma was approved by the FDA in 2011 and by the EMA in 2012: brentuximab vedotin (Adcetris ${ }^{\mathrm{TM}}$ ) [83]. This compound is a novel anti-body drug conjugate composed by a chimeric monoclonal anti-CD30 antibody, cAC10, directing this compound specifically into CD30-positive malignancies, and a cathepsin-cleavable linker as a backbone to carry monomethyl auristatin E (MMAE) [84]. MMAE is a synthetic compound derived from dolastatin 10 that was first isolated from the sea hare Dolabella auricularia with described potent antineoplastic activity [85]. The compound was later shown to be produced by the cyanobacteria Symploca hydnoides and Lyngbya majuscula, which are part of the sea hare's diet [86].

\section{Natural compounds with anti-obesity properties}

Many natural compounds have been studied that demonstrated interesting activities for the prevention and treatment of obesity and related metabolic complications as T2DM and cardiovascular disease. Most of the research employed in vitro methodologies (e.g. modulation of the differentiation of 3T3-L1 cell line), in vivo techniques (e.g. adipose mass tissue decreases in mice or rats), or direct enzymatic assays (e.g. lipase activity screening).

In our bibliographic research, we noted that the largest group of origin for anti-obesity natural compounds is plants, followed by marine algae, fungi and animals (summarized in Figure 1).

Some of the latest literature describing anti-obesity natural products has shown promising activities, through direct hormone sensitive lipase or pancreatic lipase inhibition. Xylarenals $\mathrm{A}$ and $\mathrm{B}$, two sesquiterpenoids, isolated from the ascomycete Xylaria persicaria, were found to be selective antagonists for the neuropeptide Y5 [87], which is a receptor found in peripheral and central nervous system, involved in mediating food intake and body weight [88]. Fucoxanthin, a carotenoid from Undaria pinnatifida [89] and evodiamine, an alkaloid traditionally used in China as a "fat burner" [90] induced UCP-1 expression, and phytochemicals from the leaves of Peucedanum japonicum Thunb increased the expression of the UCP-3 gene in muscle [91]. 
The majority of the natural compounds with described anti-obesity properties described so far are phenols or polyphenols (13 out of 53, 25\%) as shown in Figure 2. Phenols and polyphenols are naturally present in a wide variety of organisms; cathechins from green tea leaves, licochalcone A from the root of Glycyrrhiza glabra, tyrosol from Rhodiola crenulata and dehydrodiconiferyl alcohol from Cucurbita moschata have anti-obesity activities. Terpenes are a representative group of natural compounds, with both neurohormonal activity, as the xylarenals A and B from Xylaria persicaria, and adipose tissue mass regulation, as for the ursolic acid from Sambucus australis Cham. Diarylheptanoids and polyketides, as moccasin and ankaflavin from the mold Monascus sp., are two distinct small classes of secondary metabolites that together compose about $6 \%$ of the compounds with anti-obesity activity.

The origin of natural organisms with anti-obesity activities, either through their extracts, fractions or isolated compounds, is presented as their geographical distribution (Figure 3). Some are endemic to certain continents or countries, while others are present in many ecosystems: up to 19 out of 100 natural organisms described are ubiquitous, such as the marine algae Hematococcus pluvialis, producer of astaxanthin, and Salicornia herbacea. The greatest source of natural compound discovery is Asia, known for their ancient traditional medicine. Most of the compounds are derived from South (India) or East Asia (Japan, China, Korea), which might correlate with the lowered incidence of obesity in these countries: obese individuals represent 2 to $4 \%$ of the adult population in these countries, whereas in countries like Mexico, New Zealand and the United States, they represent about 18\% (OECD, 2014).

In the next sections, we explore compounds produced by different organism structured as follows: marine animals, marine algae, cyanobacteria, fungi, and plants.

\subsection{From marine animal origin}

Animals are a important part of human's diets all over the world due to their valuable nutritional components. Their pharmaceutical potential has been explored and numerous compounds may have important interactions with the human organism, both nutritionally and metabolically.

\subsubsection{PUFA's and crude oils from fish and crustacean}

Cholecystokinin (CCK), a brain-gut peptide, inhibits food intake in rats through the activation of peripheral CCK1 receptors [92]. Recent research indicated that peptides from protein hydrolysates of shrimp (Penaeus aztecus) heads were an effective agent, which stimulated the CCK release in intestinal cancer cells [93].

Nutritional studies indicate that diets high in content of saturated fats lead to increases in adipose tissue mass. In contrast, polyunsaturated fatty acids (PUFA) consumption, lead to decreasing deposition of adipose tissue. In particular, two long chain n-3 PUFA, eicosapentaenoic acid (EPA; 20:5 $\mathrm{n}-3$ ) and docosahexaenoic acid (DHA, 22:6 n-3) from marine fish oil were studied in mice and 3T3-L1 pre-adipocytes, and increased mitochondrial genes and PPAR $\gamma$ in white adipose tissue, which suggested upregulation of mitochondrial biogenesis and induction of $\beta$-oxidation [94]. Further studies of these two PUFA's revealed that short-term supplementation leads to significant increases of adiponectin that correlates with higher fatty acid breakdown, without anti-inflammatory effects $[95,96]$. More recently, these two PUFA's were shown to decrease lipid and cholesterol biosynthesis in the liver of dietary obese mice, pointing them as a reliable therapeutic approach for non-alcoholic fatty liver disease (NAFLD) [97].

Oils with high content of n-3 PUFA's from marine zooplankton have been studied, in particular from the copepod Calanus finmarchicus. Supplementation of crude Calanus finmarchicus oil showed improved glucose tolerance and decreases in abdominal tissue mass and adipose tissue inflammation in diet-induced obese mice [98]. However, Calanus oil is composed by several other components, other than PUFA's (roughly $80 \%$ ) such as monounsaturated fats, antioxidants as astaxanthin, and phytosterols. PUFA's of Calanus oil are bound to aliphatic long-chain monounsaturated alcohols as wax esters. Hoper and co-workers [99] demonstrated that wax esters had the same beneficial effects as crude Calanus oil, reducing body weight gain, abdominal fat, liver triacylglycerol and macrophage infiltration in fat depots. Proinflammatory genes were downregulated, whereas adiponectin expression was upregulated, which provided evidence that PUFA's cannot be accounted exclusively for its beneficial metabolic effects; in fact, wax esters are an important component of these oils [99].

Glucosamine is a derivate of chitin, a biopolymer from the exoskeleton of marine invertebrate animals, used as a nutritional supplement and for numerous medical applications due to its effects on cell proliferation and osteoblastic differentiation [100]. Recently, derivatives of glucosamine were found to inhibit adipocyte differentiation, possibly via AMP-activated protein kinase, which regulates glucose and lipid homeostasis in adipocytes [100].

\subsubsection{Marine sponges}

Marine sponges have been a fruitful source of bioactive compounds. They are sessile filter feeders with highly effective defence mechanisms against viruses, bacteria or eukaryotic organisms, and with a high content in secondary metabolites [101]. Dysidine is a sesquiterpene quinone found in Hainan sponge Dysidea villosa in the Chinese South Sea. Its anti-obesity potential was studied in differentiated 3T3L1 cells and resulted in the increased deposition of GLUT4 in the cellular membrane [102]; this correlates to higher insulin sensitivity and could be a potential compound for the treatment of T2DM. Heterofibrins are a group of bioactive compounds from the southern Australian marine sponge Spongia (Heterofibria) $s p$. and were found to be inhibitors of lipid-droplet formation in the A431 fibroblast cell line [103]. Phorbaketal A is a compound, which promotes osteogenic differentiation, through the transcriptional coactivator with PDZ-binding motif (TAZ), involved in cell differentiation and proliferation [104]. This compound, isolated from the marine sponge Phorbas sp. was found to block adipogenic differentiation in the fibroblastic C3H10T1/2 cell line, by increasing the expression of TAZ [105].

Another compound from marine sponges was found to be a possible alternative to orlistat, one of the most common pharmaceuticals for obesity treatment. Methyl xestospongic is an ester from the marine sponge Xestospongia testudinaria 
that showed inhibitory activity against pancreatic lipase, the essential enzyme for lipid digestion in the intestinal tract [106].

Bioactive compounds from marine sponges could also be a major tool for studying the metabolism of prescription drugs. A series of 4-methylenesteroid derivatives isolated from Theonella $s p$. are novel pregnane-X-receptor (PXR) modulators [107]. PXR is a gene involved in the metabolism of xenobiotics and endobiotics as bilirubin, bile acids, glucose and lipids. Studying the molecular basis of its interactions with external compounds could be of great importance for therapeutic drug development for human diseases as T2DM and obesity.

\subsubsection{Tunicates}

Another novel group of natural compounds are meridianins (A-G), marine indole alkaloids isolated from the tunicate Aplidium meridianum. Meridianins are potent kinase inhibitors [108] with described anti-cancer activity [109]. In particular, derivatives of meridianin $\mathrm{C}$ showed strong inhibition of lipid accumulation during 3T3-L1 preadipocyte differentiation and lowered leptin expression [110]. Even though this compound was found to be cytotoxic, it is highly interesting to explore this compound on a mechanistic level since it influenced important differentiation pathways as C/EBP- $\alpha$, PPAR $\gamma$ and fatty acid synthase [110].

Resuming, marine animals are a promising source of compounds with possible anti-obesity properties. Bioactive compounds are mostly identified from marine sponges, followed by crustaceans, fish oils and tunicates (Figure 4).

\subsection{From Fungi}

Organisms classified as Fungi belong to a kingdom that includes eukaryotic organisms as yeasts, moulds and mushrooms. Organisms in this category have also become very attractive for their medicinal and health-stimulating properties.

Monascus is genus of mold used as a traditional food fungus widely consumed in East Asia as health supplements and for their pigments that can be used as natural colorants [111]. The effects of the aminoacids L-tryptophan and Lleucine ethyl ester derivatives have shown to decrease serum total cholesterol and triglyceride levels in mice in vivo. In in vitro assays, high inhibitory activities were observed against lipoprotein lipase and 3-hydroxy-3-methyl-glutaryl-CoA reductase (HMG-coA reductase), an important enzyme in the metabolic pathway that produces cholesterol [112]. Monascus-fermented products are increasing in number, and red mold dioscorea (RMD, known as Monascus purpureusfermented Disocorea batatas) had mild hypolipidemic activities [113]. The isolated compounds from the Monascus-fermented product, moccasin and ankaflavin, are two polyketides thought to be responsible for the bioactivity of red mold dioscorea, since they inhibited adipose tissue differentiation and lipogenesis in vitro [113].

Deep sea water has been a part of many research studies for therapeutic approaches on lifestyles diseases. An experimental group of obese mice $(\mathrm{ob} / \mathrm{ob})$ was treated with deep sea water with high hardness for 84 days. As result, the body weight gain decreased significantly, as well as plasma glucose levels compared to the control group. The deep sea water treatment decreased plasma protein levels of resistin, increased plasma levels of adiponectin and GLUT4 in skeletal muscle, which demonstrated the potential of deep sea water to attenuate T2DM, obesity and cardiovascular diseases [114]. The interesting effect of deep sea water ( $\geq 200 \mathrm{~m}$ in depth) could be due to its high purity, abundant nutrients and minerals; it has already been useful in the agriculture, pharmaceutical and cosmetic industries [115, 116]. Following this study, deep sea water was used to raise RMD, in order to assess if deep sea water could enhance the anti-obesity potential of moccasin and ankaflavin. Both in vitro and in vivo higher beneficial effects of deep sea watercultured RMD were observed, compared to ultra-pure watercultured RMD [117].

Xylarenals A and B are two novel sesquiterpenoids, isolated from the ascomycete Xylaria persicaria, that are selective antagonists for the neuropeptide Y5 [87], a receptor found in peripheral and central nervous system, and involved in mediating food intake and body weight [88]. Ternatin is a cyclic heptapeptide isolated from the mushroom Coriolus versicolor. Treatment of diet-induced obese mice suppressed the increase in body weight and fat accumulation [118]. A study of structure-activity relationship of ternatin derivatives was performed and showed that a naturally occurring amino acid $\left(\beta-\mathrm{OH}-\mathrm{D}-\mathrm{Leu}^{7}\right)$ is a potent inhibitor of fat accumulation in 3T3-L1 adipocytes [119]. A methanol extract from the mushroom Phellinus linteus fruiting body exhibited a high lipase inhibitory activity, which is a highly important mechanistic potential for anti-obesity drug development [120]. The bioactive compound responsible is yet to be elucidated. Dietary intake of powdered whole Panellus serotinus (Mukitake) reportedly attenuated NAFLD in obese, diabetic $\mathrm{db} / \mathrm{db}$ mice [121]. When fractions of the extracts of Mukitake extracts were studied, the water-soluble extract and the ethanol-soluble extract had beneficial effects in the $\mathrm{db} / \mathrm{db}$ mice and significantly reduced hepatic triglyceride content. The water soluble Mukitake extract decreased the serum level of monocyte chemoattractant protein-1, which is known to be responsible for insulin resistance, while the ethanol soluble Mukitake extract lead to increased levels of circulating adiponectin [122]. Consumption of Grifola frondosa is very common in East Asia, as a traditional beneficial medicine food. Polysaccharides from Grifola frondosa, also known as Maitake, exerted hypoglycaemic activity in HepG2 cells [123]. Glucose uptake was enhanced in a dose-dependent manner and the insulin receptor protein in the cell membrane was activated. In another study using high-fat diet fed and streptozotocin-induced hyperglycaemic mice, a non-polar fraction of Grifola frondosa significantly lowered blood glucose level, serum total cholesterol, and showed a strong anti- $\alpha$-glucosidase activity, an enzyme that acts on the breakdown of starch and disaccharides [124]. Recently, a water extract of a mushroom used in traditional Chinese medicine (Ganoderma lucidum) was demonstrated to reduce body weight, inflammation and insulin resistance; the obesity induced gut dysbiosis (ratio of Bateroidetes to Firmicutes) was reversed in mice, and a high molecular weight polysaccharide $(>300 \mathrm{kDa})$ isolated from this extract was stated as the possible responsible compounds for the anti-obesity and microbiota-modulating effect [125].

Most of the described mushrooms are part of the East Asian cuisine. Interestingly, mushrooms are a reliable source of anti-obesity compounds and might be a favourable 
addition to Western food habits, where the obesity epidemic is more prevalent.

\subsection{From Marine Algae}

Marine algae are geographically widespread organisms that can be divided in two groups: micro- and macroalgae (seaweeds). Macroalgae are benthic organisms present in seawater or brackish water and comprise approximately 6000 species. They are divided into three main classes green (chlorophytes), red (rhodophytes) and brown (phaeophytes) algae. The traditional consumption of seaweed in eastern Asia may be linked with the lower incidence of metabolic syndrome. Tororokombu, for example, is a traditional Japanese food from the 1620 s, made by edible kelp, a type of large seaweeds. The non-shaved version has powerful antiobesity effects decreasing serum triglyceride levels [126]. The main compound in seaweeds is fibre, with varying content of soluble and non-soluble fibres dependent from species. Fibres in diet can prevent metabolic syndromes associated to obesity (T2DM and cardiovascular complications). Fibres are typically low in fat and lipids, and very rich in nutrients as magnesium and polyphenols. Interesting compounds as fucoxanthin, fucosterol or polyphenols are recognized as nutraceutical compounds from seaweeds. Some of them interact with peroxisome proliferator-activated receptors (PPARs), which are a superfamily of nuclear hormone receptors of ligand-activated transcription factors. They are widely studied targets for treatment of T2DM and dyslipidaemia, and isotypes as PPAR $\alpha$ and PPAR $\gamma$ are associated with fatty acid oxidation, and lipid synthesis, respectively. An Undaria pinnatifidaderived fucoxanthin-enriched ethanoic extract effectively reduced body and abdominal white adipose tissue weights, plasma and hepatic triglyceride and cholesterol in high-fat diet fed mice [127]. As we explored before (Section 2.1), one promising molecular target for anti-obesogenic drug discovery could be the induction of UCP-1 in white adipose tissue. Genomic studies actually showed that fucoxantin induced UCP-1 expression in mitochondria of abdominal white adipose tissue, which caused the oxidation of fatty acids and thermogenesis [89].

Some compounds are geographically ubiquitous and found in many trophic levels of the food chain, due to bioaccumulation. Astaxanthin, a xantophyll carotenoid with anti-oxidant and anti-inflammatory properties, mainly produced by the marine algae Hematococcus pluvialis, but also found in many krill species as Euphausia pacifica, Euphausia superba and Pandalus borealis, the yeast Xanthophyllomyces dendrorhous, and in salmon, trout and crustaceans. Astaxanthin has been reported to have antiobesity properties, it inhibited increases in body weight and adipose tissue mass in high-fat diet fed mice and lowered liver and plasma triglyceride level and total cholesterol [128]. More recently, a part of the molecular mechanism was elucidated for astaxanthin effects; increased insulin sensitivity, enhanced the autophosphorylation of insulin receptor- $\beta$, the GLUT-4 translocation in skeletal muscle and the IRS-1 phosphatidylinositol 3-kinase step, a pathway responsible for glucose uptake, lipogenesis and glycogen synthesis [129].

Eisenia bicyclis is a marine brown alga from the Pacific coast around Korea and Japan. Its methanolic extract, composed mainly by phlorotannins (as eckol, bieckol, fucofuroeckol A, 7-phloroeckol, dioxindehydroeckol and phlorofucofuroeckol A), inhibited pancreatic lipase [130]. Purified phlorotannins suppressed the differentiation of 3T3L1 adipocytes in a dose-dependent manner, without any toxic effects, and 6,6'-bieckol was responsible for the most significant results [131].

The anti-obesity potential of Laminaria japonica Areshoung, a traditional Korean marine brown algae, was evaluated in Sprague-Dawley male rats, and caused decreasing body weight gain, serum and hepatic lipid levels and, at the cellular level, decreasing number of lipid droplets and adipocyte size [132].

Numerous compounds from the brown alga Ecklonia cava have been isolated and studied for activity. The phloroglucinol derivative, 1-(3',5'-dihydroxyphenoxy)-7(2",4",6-trihydroxyphenoxy)-2,4,9-trihydroxydibenzo-1,4dioxin [133] and dioxinodehydroeckol [134] inhibited lipid accumulation during adipogenesis and downregulated genes associated with adipogenesis in 3T3-L1 cells. Phlorotannins were isolated from this brown alga, reduced the lipid accumulation and glucose consumption in 3T3-L1 adipocytes and suppressed adipogenic transcription factors as PPAR $\gamma$ and SREBP-1 [135].

Fucosterol, isolated from Ecklonia stolonifera, also inhibited adipocyte differentiation and lipid formation, since it inhibits expression of PPAR $\gamma$ and $\mathrm{C} / \mathrm{EBP} \alpha$ in a concentration-dependent manner, without any cytotoxicity [136].

Sargassum is a genus of approximately 250 species of brown algae that has been at the centre of obesity research. In 2008, the plastoquinones, sargaquinoic acid and sargahydroquinoic acid, isolated from Sargassum yezoense were identified as novel PPAR $\alpha / \gamma$ dual agonists, with a binding affinity even higher than the specific PPAR $\gamma$ agonist troglitazone. In the 3T3-L1 cells, exposure to both compounds increased adipocyte differentiation and mRNA expression of adipogenic marker genes [137]. In contrast, extracts of a further Sargassum species (Sargassum thunbergii) were studied in 3T3-L1 fibroblasts, and were responsible for the inhibition of lipid accumulation and suppression of adipogenesis genetic markers [138]. Some monoglactosyldiacylglycerols from the brown alga Sargassum horneri inhibited also triglyceride accumulation and free fatty acid levels in 3T3-L1 adipocytes [139].

Fucoidan is a group of sulphated polysaccharides from marine brown algae that have various medicinal applications $[140,141]$. The main active compounds are L-fucose (sugar) and sulphate ester groups, which showed impairment of 3T3L1 pre-adipocyte differentiation [140]. The inhibitory effect of this compound was later elucidated: fucoidan increased hormone sensitive lipase in differentiated 3T3-L1 treatedadipocytes, suggesting stimulation of lipolysis [142].

Polysaccharides from Ulva lactuva decreased blood glucose level in adult rats, due to a strong inhibition of enzymes related to starch digestion [143].

Food for male Wistar rat was supplemented with dried Ulva ohnoi (UO) and Derbesia tenuissima (DT), after 16 weeks of a corn starch-rich diet or a high-carbohydrate, highfat diet with drinking water supplemented with fructose. Supplementation with UO lowered final body fat mass and 
improved glucose metabolism and insulin sensitivity. In contrast, supplementation with DT did not change the total body fat mass but decreased plasma triglycerides and total cholesterol [144].

Siphonaxanthin, a xanthophyll common to green algae species, was studied in vitro and in vivo, and suppressed preadipocyte differentiation in 3T3-L1 cells, and lowered white adipose tissue weights in diabetic KK-Ay mice [145].

\subsection{From cyanobacteria}

Some strains of cyanobacteria are commercially available for consumption due to their beneficial properties to human health, e.g. Arthrospira, Nostoc and Aphanizomenon [146]. Cyanobacteria contain bioactive and beneficial components as carotenoids, $\gamma$-linoleic acid, phycocyanin, fibers, and plant sterols [147]. Arthrospira, previously known as Spirulina, is a filamentous cyanobacteria belonging to the class III (Oscillatoriales) which is usually found in high salt-alkaline water bodies. Its use as a traditional food in Central Africa, and studies that demonstrated its beneficial effects on human health has led to its consumption worldwide. The therapeutic effects, generally comprising the major three species Arthrospira platensis, Arthrospira maxima, Arthrospira fusiformis, include anti-hypercholesterolemia, antihyperglycerolemia, anti-inflammatory, anti-tumor and antiviral activities; it is also protective of cardiovascular diseases, mainly due to its hypolipidemic, anti-oxidant and anti-inflammatory activities [148]. Many preclinical studies have been performed in various animal models and demonstrated a hypolipidemic activity of Arthrospira. Arthrospira is well recognized for its high protein content and its richness in minerals, essential fatty acids and carotenoids, as $\beta$-carotene, astaxanthin and canthaxanthin [149], phycobiliproteins as c-phycocyanin phenolics as synapic, chlorogenic and caffeic acids, and anti-oxidant vitamins as Vitamin E .

Studies revealed that supplementation of the diet with Arthospira species, significantly ameliorated the hyperlipidemic profiles of high fat/high cholesterol diet, high fructose and high sucrose diets, and carbon tetrachlorideinduced fatty livers in rats and mice, lowering hepatic cholesterol and triglyceride levels [150-154].

These promising results were confirmed in human clinical trials, where supplementation with Arthrospira species resulted in decreases of plasma triglyceride concentrations and of the ratio of high and low density lipoprotein in subjects with T2DM. Arthrospira also presents a high content of $\gamma$-linoleic acid (around 1.3\%), which is frequently used to treat rheumatoid arthritis, atopic eczema, acute respiratory distress syndrome, cancer, and asthma, and to improve plasma lipid profiles [155].

Recent studies reported that the in vitro and in vivo antidiabetic effect of Arthrospira could be from the active component phycocyanin, a phycobiliprotein that lowered body weight, serum and liver triglyceride content and fasting plasma glucose in KK-Ay mice (KK mice strain with the yellow obese gene $A^{y}$ ), most likely by enhancement of insulin sensitivity [156]. However, the inherent high polysaccharide content itself has the capacity of lowering insulin and glucose blood levels and to promote cholesterol elimination in feces [157].
The major component of Spirulina, phycocyanin, accounting for $14 \%$ of the cyanobacteria's dry weight [158], has been reported to be a potent anti-inflammatory agent, which abolished the TNF- $\alpha$ response in Kupffer cells from mouse liver after induction of thyroid calorigenesis [159], and reduced inflammatory cell infiltration and colonic damage in rats with acetic acid induced colitis [160]. Other studies described phycocyanin as a powerful antioxidant agent with neuroprotective effects, able to scavenge reactive oxygen species [161].

Diet supplementation with Nostoc commune var sphaeroides Kützing (N. commune) demonstrated hypocholesterolemic activity in mice, reduced intestinal cholesterol absorption and stimulated fecal sterol excretion [162]. Its lipid extract significantly lowered the expression of HMG-CoA reductase, a key enzyme for cholesterol biosynthesis, and the levels of mature forms of SREBP-1 and SREBP-2, leading to a decreased mRNA expression of genes involved in the cholesterol and fatty acid metabolism [163]. Furthermore, the lipid extract of $N$. commune reduced the mRNA expression of proinflammatory genes, evaluating the levels of proinflammatory mediators as TNF- $\alpha$, COX-2, IL$1 \beta$, IL-6 in RAW 264.7 macrophages in a dose-dependent manner [164]. The anti-inflammatory activity may be mediated, at least in part, by inhibiting the NF-KB pathway in order to decrease the production of proinflammatory mediators [147].

Cyanobacteria have a strong potential to possess further unknown bioactive compounds with anti-obesity, antiinflammatory or anti-oxidant properties. Safety assessments of certain cyanobacteria strains are now performed, in order to evaluate if dietary supplementation of cyanobacteria may be consumed without toxic side-effects [165].

\subsection{From plants}

As was elucidated in the Table 2, plants are the main source of natural compounds with anti-obesity properties. In around $15 \%$ of the studies, the whole plant was used to screen for activity (stem, leaves and flowering parts); in other studies the anti-obesity activity assessment focused on a single part of the plant as seeds, leaves, fruits or roots. Furthermore, formulations exist from different plants as for the Egyptian herbal mixture formulation, composed of $T$. chebula, Senae, rhubarb, black cumin, aniseed, fennel and liquorice. Such mixture formulation normalized lipid profiles in diet induced-obese rats and lowered body weight and metabolic complications of obesity, as defective antioxidant stability and high values of insulin resistance parameters [166].

Known beneficial plants as ginseng are known to contain a high variety of bioactive saponins and glycosides with foaming properties. Two major compounds saponins, protopanaxadiol and protopanaxatriol, were tested in dietinduced obese Sprague-Dawley rats and reduced body weight, total food intake, fat contents and serum cholesterol and leptin level. Neurohomone levels were also assessed in this experiment and revealed that mRNA expression of orexigenic neuropeptide $\mathrm{Y}$ was significantly decreased with both protopanaxadiol and protopanaxatriol, whereas the mRNA level of anorexigenic cholecystokinin increased, compared to the high fat diet group [167]. These results suggest that saponins from ginseng have anti-obesity 
properties by modulating hypothalamic neuropeptides and inhibiting energy input, through the alteration of important targets for anti-obesity drug development. Activity guided fractionation of extracts of Vitis coignetiae Pulliat resulted in the isolation of resveratrol, that was found to have similar activities, resulting in the inhibition of neuropeptide $\mathrm{Y}$ and agouti-related protein, two hypothalamic neuropeptides that stimulate food intake [168]. Resveratrol also inhibits fatty acid synthase and activates Sirt-1; alteration of both targets leads to decreased adipogenesis [169]

Galangin is a flavonol glycoside isolated from Alpinia galanga Willd, a native plant cultivated in Malaysia, India, Indochina and Indonesia, used as a traditional remedy for many diseases as obesity and T2DM. It was shown to have, in fact, in vitro pancreatic lipase inhibitory activity. In in vivo experiments with female albino rats, galangin inhibited increases in body weight and decreased serum lipids, lipid peroxidation and accumulation of hepatic triglycerides [170]. Ursolic acid is a pentacyclic titerpenoid. When adult male Swiss mice were treated with ursolic acid extracted from the aerial parts of Sambucus australis Cham. from Brazil, body weights decreased, as well as visceral adiposity and level of blood glucose relative to their controls: amylase and lipase activities also decreased, whereas plasma leptin levels were higher [171]. A water soluble extract prepared from the stem parts of Cucurbita moschata, a species of pumpkin, exerted anti-obesity activities in high fat diet-induced obese mice, suppressing body weight and fat storage, while food intake did not change. The water extract was protective against the development of fatty liver disease, and increased hepatic $\beta$ oxidation and decreased lipogenic genes as SREBP-1 [172]. In 2012, the responsible compound for the anti-obesity activity of Cucurbita moschata was elucidated, after solvent fractionation. Dehydrodiconiferyl alcohol (DHCA), a polyphenol, significantly decreased the expression of adipogenic marker genes and the lipid accumulation, while maintaining cell viability [173]. Treatment with DHCA also suppressed the proliferation of 3T3-L1 cells and primary mouse embryonic fibroblasts, lowering the expression of cell cycle marker genes, as cyclin-dependent kinase 2 [173].

Spergularia marina is a flowering plant popular in South Korea, recognized as a beneficial source of amino acids, vitamins and minerals. Treatment of 3T3-L1 fibroblasts with $S$. marina whole extract significantly reduced lipid accumulation and decreased adipogenic gene levels and was further seen to increase osteoblastogenic differentiation in MC3T3-L1 pre-osteoblasts, increasing levels of osteoblastogenesis markers [174]. Another plant extract was also used to study both adipogenesis and osteoblastogenesis. Salicornia herbacea extract reduced lipid accumulation and inhibited gene expression of PPAR $\gamma, \mathrm{C} / \mathrm{EBP}-\alpha$ and SREBP1. On the other hand, activity of alkaline phosphatase, an osteoblastogenic marker, was increased by $120 \%$ at a concentration of $100 \mu \mathrm{g} / \mathrm{mL}$ in differentiating osteoblasts [175].

Indole-3-carbinol is a compound present in various vegetables. The compound was tested in male C57BL/6 mice treated with a high fat diet and decreased body weight and epididymal adipose tissue weight. Mice from the high fat diet group treated with indole-3-carbinol also had improved glucose tolerance and modulated expression of adipokines and adipogenic-associated genes, as PPAR $\gamma$ [176].
Shikonin (5,6-dihydroxyflavone-7-glucuronic acid), the main compound of the Japanese plant Lithospermum erythrorhizon, was tested in the differentiation of 3T3-L1 adipocytes. It inhibited the formation of lipid droplets and accumulation of triglycerides and the expression of regulators of adipogenesis as SREBP-1C, PPAR $\gamma$ and C/EBP- $\alpha$ [177]. Using the same in vitro model system, the inner bark extract of the trees Populus balsamifera and Alnus incana were analysed. The extract of Alnus incana was a partial agonist towards PPAR $\gamma$, while Populus balsamifera extracts significantly inhibited the adipogenesis, and acted as antagonist of PPAR $\gamma$ [178]. Tyrosol, a major bioactive phenolic compound from Rhodiola crenulata, disrupted the energy generation by the pentose phosphate pathway in 3T3$\mathrm{L} 1$ adipocytes, which led to the suppression of adipogenesis and lipid accumulation [179]. The Rhodiola extract also increased the superoxide dismutase activity in a dosedependent manner, resulting in lowered reactive oxygen species during adipogenesis [179].

The ethanol extract of Taraxacum officinale, also known as dandelion, was tested for its inhibitory potential against pancreatic lipase. In vitro studies showed inhibitory activities of pancreatic lipase in a dose dependent manner and in vivo studies confirmed inhibitions of plasma triglyceride levels after ingestion [180]. Ethanol extracts from flower buds of Splilanthes acmella also had an inhibitory activity towards pancreatic lipase in a concentration-dependent manner [181].

\subsubsection{From fruits}

Fruits are an important source of anti-obesity compounds. Fruits are part of the flowering plant and disseminate seeds for species propagation. Fruits have high contents of water, carbohydrates in the form of simple sugars, and minerals. In our bibliographic search, they represented around 9\% of the sources with anti-obesity properties, either through the whole fruit or identified bioactive compounds, identified as described in the following.

Chlorogenic acid, commonly found in apples, pears, tomatoes and blueberries, exhibited a significant anti-obesity activity lowering body weight, visceral fat mass, plasma leptin and insulin levels in high-fat diet induced-obese mice. Triglyceride content in adipose tissue was also significantly lowered, as well as the activity of fatty acid synthase, HMGCoA reductase and acyl-CoA:cholesterol acyltransferase, while fatty acid $\beta$-oxidation and PPAR $\alpha$ expression was increased in the liver. These results underline the complex interactions of anti-oxidants with the lipid metabolism and hints on mechanistic pathways towards its anti-obesity profile [182]. Evodiamine is an alkaloid from the fruits of Evodia rutaecarpa, a traditional Chinese medicine, known as a "fat burner". In fact, its potential was confirmed to decrease body weight, perirenal and epididymal fat mass, and serum levels of free fatty acids, triglyceride and cholesterol in the liver [90]. More interestingly, evodiamine treatment significantly increased specific guanosine-5'triphosphate (GDP) binding in the mitochondria of brown adipose tissue, which is a modulator of UCP-1 [90]. Another study evaluated the effects of Psidium guajava puree, also known as pink guava, in high fat diet induced-obese rats. Pink guava puree reduced body weight, glucose levels, total cholesterol and systolic blood pressure, compared to control. Antioxidant enzymes, as glutathione peroxidase and 
superoxide dismutase, had also higher activities after treatment of high fat diet induced-obese rats with pink guava [183].

Mulberries, known for their antioxidant compounds, were analysed for anti-obesity activity. Their water extract reduced lipid accumulation, suppressed fatty acid synthesis and stimulated fatty acid oxidation in HepG2 cells. The suggested mechanism for the activity of mulberry water extract is via phosphorylation of adenosine monophosphateactivated protein kinase [184]. In 2013, a study reported that 1-deoxynojirimycin extracted from mulberries decreased visceral fat weight and the size of adipocytes in diet-induced obese mice and increased $\beta$-oxidation due to higher circulating levels of adiponectin [185]. Furthermore, 1deoxynojirimycin decreased glucose absorption in the intestinal cells, while at the hepatic level, the activity of glycolysis enzymes increased and the activity of gluconeogenesis enzymes decreased [186].

Using cell lines as in vitro model system, 3T3-L1 cells were treated with raspberry ketone, a phenolic compound isolated from the red raspberry, in order to elucidate its mechanism; differentiated adipocytes showed increased lipolysis and secretion of adiponectin, which is involved in fatty acid breakdown [187]. Garcinia cambogia's fruit extract had also potential as anti-obesity nutraceutical, since it inhibited lipid droplet accumulation, without affecting the differentiation of adipocytes [188].

The shell of the peanut (Arachis hypogaea), when extracted in $95 \%$ ethanol, had inhibitory activity against pancreatic lipase and lipoprotein lipase. Wistar rats treated with the peanut shell extract had increased fecal lipid excretion, which confirms the inhibitory activity on lipases [189].

\subsubsection{From roots}

The physiological functions of roots are the absorption of water and inorganic nutrient and the storage of organic nutrients. Roots have symbiosis with bacteria and fungi, which may represent the ecological advantage of containing a high content of secondary metabolites and nutrients.

Prunetin, a known isoflavone found in peas, showed antiobesity properties, significantly reducing body weight gain in mice fed with a high fat diet, inhibiting the high fat dietinduced upregulation of the expression of adipogenic genes and inducing expression of adiponectin receptors [190].

Phytochemicals from ginger, as 6-gingerol, zerumbone and the rhizome extract of a plant of the ginger family, reduced significantly the increases in adipose tissue mass in high fat diet-induced obese mice and targeted the cholesterol metabolism and the fatty acid breakdown by increasing the activity of key enzymes [191]. Ursolic acid isolated from the roots of Actinidia arguta, also known as hardy kiwi, inhibited the increase of triacylglycerol levels after oral administration of a lipid emulsion in rats [192]. The authors discuss that the protective activity observed in this study might be attributed to the inhibition of lipid absorption in intestinal cells, possibly by inhibition of pancreatic lipase.

The benefits of phytochemicals like curcumin on human health have been intensively studied. Curcumin reduced chronic inflammation, which is associated with obesity. Curcumin ameliorated insulin resistance in genetically obese mice and diet-induced obese mice, and had significantly reduced macrophage infiltration within the white adipose tissue that links with lowered local inflammation [193]. Curcumin suppressed differentiation of 3T3-L1 preadipocytes by reducing the number of mature adipocytes and fat content, assessed by Oil Red O staining [194]. Curcumin treatment also inhibited the mRNA expression of key adipogenesis genes as PPAR $\gamma$ and C/EBP- $\alpha$.

Tanshinone IIA is an herbal compound, abundant in the root of Salvia miltiorrhiza, used in traditional Chinese medicine to treat cardiovascular diseases. Tanshinone exerts anti-oxidant and anti-inflammatory effects. It suppressed adipogenesis through inhibition of PPAR $\gamma$ in 3T3-L1 adipocytes, and reduced adipose mass tissue and body weight, and improved glucose tolerance in high fat dietinduced obese mice [195].

Polygonum cuspidatum is a medicinal plant commonly used in East Asian countries. The n-butanol fraction of the Polygonum cuspidatum extract exerted significant inhibitory activities on adipogenesis in a dose-dependent manner, evidenced by the reduced formation of lipid droplets and decreased glycerol-3-phosphate dehydrogenase activity. Adipogenesis marker proteins and genes were also decreased [196].

Licorice, a well-known sweet flavour, is the root of Glycyrrhiza glabra. After some studies described the metabolic benefits of liquorice extract, in 2014 the responsible compound was elucidated: $18 \beta$-glycyrrhetinic acid. It suppressed anadamide-induced 3T3-L1 adipocyte differentiation, a cannabinoid receptor type 1 agonist, and downregulated adipogenic genes and the protein levels of fatty acid synthase and stearoyl-CoA desaturase 1. The animal model confirmed these results, showing that supplementation with $18 \beta$-glycyrrhetinic acid resulted in decreases of body weight, fat weight and plasma lipid levels in high-fat diet induced obese mice [197]. The anti-obesity properties of licochalcone A, a natural phenol also from the root of Glycyrrhiza glabra, were assessed in 3T3-L1 adipocytes and resulted in reduced lipid accumulation and down regulation of the expression of key adipogenic genes and receptors [198]. The analysis in high-fat diet induced obese mice confirmed the anti-obesity effect of licochalcone A by decreasing their body weight and plasma triglyceride, and cholesterol level [198].

1 '-acetoxychavicol acetate is an ester naturally found in Alpinia galanga and Languas galangal, two plants from the ginger family used in Thai and Indonesian cuisine. The effects of this antioxidant were studied in 3T3-L1 adipocytes and lowered lipid accumulation through the down-regulation of PPAR $\gamma$ and C/EBP- $\alpha$ in the mature adipocytes. In high fat diet-fed rats 1'-acetoxychavicol acetate lowered the activity of glycerol-3-phosphate dehydrogenase, which is involved in carbohydrate and lipid metabolism. Steatohepatitis did not occur in the treated rats, which indicates that this compound may be preventive against metabolic disease [199].

\subsubsection{From leaves}

Leaves represented around $13 \%$ of the sources of antiobesity compounds and around $23 \%$ of the compounds described from plants. Leaves are an important organ of vascular plants composed by the epidermis, the mesophyll tissue, where the chloroplasts are found, and veins. Leaves 
are worldwide consumed as source of beverages as in herbal teas and recognized for their numerous and versatile benefits. Tea leaves are rich in tea chatechins, which are antioxidant phenols, e.g. gallocatechin gallate, catechin gallate and epigallocatechin gallate. Biosynthesis of important flavonoids also takes place in leaves, as for anthocyanin, which is increased under stress [200]. The prevalence of complex compounds in leaves is to be expected, since they are exposed to many environmental stresses as high irradiances, UV radiation, water stress and mechanical injury, as well as biotic stresses such as herbivory and pathogen attack.

Vernonia amygdalina is a small shrub typical from tropical Africa. Its leaf powder was added to the diet of dietinduced obese rats for 4 weeks and resulted in a decrease of body weight gain, serum triacylglycerol, serum and brain total cholesterol; effects were stronger than by the antiobesity drug orlistat also tested in this study [201]. Administration of pu-erh tea in rats with high fat dietinduced obesity significantly reduced the total body weight, plasma total cholesterol, triglyceride concentrations and lowdensity lipoprotein-cholesterol, suggesting an attenuating effect on fat levels and accumulation [202].

The leaves of Peucedanum japonicum Thunb (PJT) are traditionally consumed in Okinawa Island (Japan) due to its health benefits. The administration of powdered PJT inhibited high fat diet-induced obesity in mice [203] and phytochemicals present in the ethanol extract exerted promising activities in C57BL/6 mice. The ethanol extract decreased fat accumulation and adipocyte size, reduced serum and liver triglyceride concentrations and inhibited the overall obesity. The PJT ethanol extract also inhibited lipase activity in vitro and increased the expression of the UCP-3 gene in muscle of high-fat diet-induced obese mice, which is involved in thermogenesis [91].

The dichloromethane and ethyl acetate extracts of Murraya koenigii leaves, also known as curry tree, resulted in decreases of body weight, plasma total cholesterol and triglyceride levels in high fat diet induced obese rats [7]. An extract made from two herbs widely used in East Asia, Scutellariae Radix and Platycodi Radix, was used to confirm their anti-inflammatory, anti-hyperlipidemic and anti-obesity activities. Their common component, target herbal ingredient (THI), is thought to be responsible for these activities. High fat diet-induced obese mice were orally administered a daily dose of THI for 10 weeks, which caused a reduction of body weight, improved the glucose tolerance and total serum cholesterol level [204]. In vitro tests using 3T3-L1 showed that adipogenic transcription factors were down regulated by THI in a dose-dependent manner [204].

The methanol extract of Dypsis lutescens leaves, also known as bamboo palm, showed specific in vitro inhibitory activity towards pancreatic lipase and lowered triglyceride accumulation in 3T3-L1 pre-adipocytes [205].

Houttuynia cordata Thunb., also known as chameleon plant, is an East Asian flowering plant native, used in traditional medicine. The water extract from the leaves decreased obesity symptoms in corn oil-induced obese mice, as increased plasma triglyceride and glycerol levels [206].

Maté tea, widely consumed in South America, Spain and Portugal produced from the leaves of Ilex paraguariensis, showed strong effects on porcine and human pancreatic lipase activity in vitro and also ameliorated the increases in body weight and unhealthy lipid profile of diet inducedobese mice [207].

Other herbal medicines from China, as Inchinko-to, Bofu-tsusho-san and Dai-saiko-to, are used as therapeutic or preventive agents for various diseases. Their health benefits were investigated on male mice fed with a high-fat diet. Diets supplemented with the herbal medicines resulted in lowered plasma lipid levels, Dai-saiko-to being the most beneficial [208].

Nelumbo nucifera Gaertn. leaves, also known as sacred lotus, are used in Japan and China as a medicinal plant more recently to treat obesity. It reduced body weight, body lipid accumulation and activity of fatty acid synthase in dietinduced C57BL/6 obese mice [209]. The pharmacology of the leave extract involved inhibitory activities of $\alpha$-amylase and lipase, and stimulatory activities on the lipid metabolism and on mRNA expression of UCP-3 mRNA in diet-induced obese mice [210].

Macrostemonoside A, a steroidal saponin isolated from Allium macrostemon Bung. bulbs, a traditional Chinese medicine, showed moderate inhibition of diet-induced increases of blood glucose, liver glycogen, serum total cholesterol and visceral fat accumulation [211].

Tea leaves are rich in tea chatechins, which are antioxidant phenols. Treatment with gallocatechin gallate and catechin gallate in rats for 23 days resulted in lowered activity of enzymes related to hepatic fatty acid synthesis, as fatty acid synthase and malic enzyme, leading to decreases in hepatic triacylglycerols [212]. Epigallocatechin gallate exerted anti-adipogenic effects through the $\mathrm{WNT} / \beta$-catenin pathway, upregulating the nuclear level of $\beta$-catenin that leads to the downregulation of major adipogenic markers as PPAR $\gamma, \mathrm{C} / \mathrm{EBP}-\alpha$, fatty acid binding protein and fatty acid synthase [213].

Green tea originates from China and is made from the leaves of Camellia sinensi known for its high composition in antioxidants as phenols. Studies have shown that drinks supplemented with catechins and epigallocatechin gallate, two types of flavanols present in green tea, are effective against obesity, hypercholesterolemia and hyperglycemia [214]. Studies showed that treatment of 3T3-L1 adipocytes with green tea catechins increased the level of glycerol and free fatty acids released into the medium that correlates with enhanced lipolysis, but only in the presence of norepinephrine [215]. This shows that green tea catechins could have beneficial activities in a protein kinase Adependent pathway.

\subsubsection{From seeds}

Seeds are embryonic plants, important for the reproduction of gymnosperm and angiosperm plants. They are enclosed in a protective outer layer named the seed coat and constituted by the embryo in the inside part. Within the seed, nutrients are stored for the growth of the embryo, which varies depending on the kind of plant. Seeds are a small part of the diet of humans in general, when compared to the dietary portion represented by animals, vegetables and fruits. Some antioxidants from seeds are extensively 
described as secoisolariciresinol diglucoside, a lignan present in flax, sunflower, sesame and pumpkin seeds [216]. Flaxseed is one of the most commonly used seed in human diet, recognized as a supplement for its beneficial properties due to its high content of PUFAs, secoisolariciresinol diglucoside, phenolic acids and flavonoids. Phenolic compounds as other secondary metabolites are beneficial to the embryonic plant in their constitution in order to prevent degradation of fatty acids and other nutrients during seed storage [217].

Ethanol extracts from seeds of Afromomum meleguetta had an inhibitory activity towards pancreatic lipase in a concentration-dependent manner [181]. Fermented soybean products have been established to be beneficial for general health.

Doenjang, a seasoning used in Korean cuisine, was tested in overweight human adults and found to reduce body weight and body fat mass, mainly visceral fat [218]. Linoleic acid, an omega-3 fatty acid, extracted from flaxseed oil was determined to be an effective modulator of inflammation and adipocyte dysfunction, with some of the inflammation markers lowered 70 to $80 \%$ with the flaxseed oil treatment [219].

A water infusion of Hunteria umbellata dried seeds is used in Nigerian folk medicine as an obesity and hyperlipidaemia management procedure. Oral doses of the aqueous seed extract, with combined pre-treatment with simvastatin, significantly reduced the weight gain pattern in induced hyperlididaemic rats [220].

Deglycosylation of soygerm isoflavones, through a process of fermentation by Bifidobacterium breve, results in the formation of aglycones (as daidzein, glycitein, genistein), which are strong inhibitory compounds of pancreatic lipase, both in a fermentation-time and dose-dependent manner. Oral administration of the fermented isoflavones in rats caused decreases in triglyceride plasma levels after 2 hours of administration, when compared to the oral administration of unfermented isoflavone group, establishing the potential of the fermented isoflavones as important lipid absorption suppressants [221].

Kochujang, a seasoning used in korean cuisine, derived from fermentation of powdered red peppers and soybeans, rice syrup and rice flour for six months, has been reported to have several benefits both in vitro and in vivo. Its effects were tested in overweight men and women in a 12-week study. The kochujang-treated group showed a significant reduction in visceral fat, even though body weight did not change, and in serum triglycerides, compared to the placebo group [222].

Fenugreek seed extract was also found to reduce body weight gain in diet-induced obese mice. The major component of the extract, 4-hydroxyisoleucine, also decreased plasma triglyceride gain [223].

The anti-obesity potential of oligomeric and polymeric procyanidin fractions from grape seeds was assessed in 3T3L1 adipoyctes. Treatment resulted in lowered lipid accumulation, but not by lipolytic enzyme activity [224].

Hippophae rhamnoides, also known as sea-buckthorn, is a species of flowering plant, native to dunes and sea cliffs in Europe and Asia. A study investigated the ability of its flavone extracts from the seed residues to regulate insulin and angiotensin levels. Mice fed with a high sucrose diet showed significant rises in systolic blood pressure, plasma insulin, triglycerides and activated angiotensin in heart and kidney, showing the anti-hypertensive and antihyperinsulinemia potential of this plant [225].

The seed extract of Nelumbo nucifera was also evaluated using 3T3-L1 pre-adipocytes and the treatment significantly inhibited pre-adipocyte differentiation, in a dose-dependent manner, without showing cytotoxicity [226].

The reported anti-obesity activities are summarized in Table 2, derived from various natural resources. Most of the observed effects relied on alteration of adipogenesis, food intake, pancreatic lipase activity, improvement of insulin sensitivity, increase of UCP mRNA expression, or antiinflammatory activities. Some studies specifically revealed benefits related to the metabolic complications of obesity, as NAFLD. As ameliorated obesity symptoms, we grouped results from in vivo experiments, mainly using rats and mice as the animal model. Effects in this group include decreases of body weight gain, plasma total cholesterol, or triglyceride concentrations in animals fed with high fat diets.

\section{CONCLUSION}

The adipose tissue is a very dynamic organ, and involved in the regulation of the whole-body metabolism by secreting hormones and adipokines. Obesity is caused by an excess intake of calories and obesity is linked to various obesity-related comorbidities, e.g. T2DM, cardiovascular disease, chronic inflammation or others. Many potential drug targets exist for anti-obesity pharmacotherapy and the actually most used are 1) drugs suppressing appetite, 2) drugs reducing intestinal lipid absorption or 3) drugs increasing insulin sensitivity.

Many advances are taking place towards the development of drugs acting on specific targets for obesity treatment. Targets for obesity treatment do not include exclusively the adipose tissue. Promising drugs for weight control are focusing on pancreatic lipase inhibitors, modulation of appetite and obesitylinked behaviour through anorexigenic neuropeptides, and on transdifferentiation of beige adipocytes through UCP activation. Drugs concerning the metabolic complications of obesity as chronic inflammation, T2DM, hypertension and cardiovascular disease, focus on the dynamics of adipocyte tissue for the improvement of insulin sensitivity and adipose tissue balance, as adipocyte differentiation modulators and SGLT-2 inhibitors blocking glucose reabsorption in the proximal tubule of the nephron.

Natural compounds are a major source of many promising candidates that have beneficial influence on either obesity or obesity-related co-morbidities. In this review, we highlighted many natural sources and natural described compounds that modulate many different anti-obesity targets, cementing natural derived drugs as a major tool not only for anti-cancer, antimicrobial and anti-neurodegenerative drug development, but also as a big promise for many anti-obesity drugs. This review highlights the discovery of new bioactive compounds, generally from complex mixtures from natural resources. It is important to mention that most of the bioactive compounds will need further experiments for the study of underlying mechanism, but also of potential side effects and other safety issues. 
The further study of the molecular targets of natural antiobesity compounds with strong observed activities, offers a potential to discover new modulating compounds of several potential pathways for the treatment of this multifactorial disease. Even if not for drug development, natural dietary antiobesogenic phytochemicals may be used as nutraceuticals to help inverting the trend of an increasing incidence of obesity. An emerging trend exists for the consumption of functional foods produced by nutraceutical companies worldwide, in addition to the promotion of an active and healthy lifestyle.

\section{CONFLICT OF INTEREST}

The authors declared no conflict of interest.

\section{REFERENCES}

[1] Fox, C.S., Massaro, J.M., Hoffmann, U., Pou, K.M., MaurovichHorvat, P., Liu, C.Y., Vasan, R.S., Murabito, J.M., Meigs, J.B., Cupples, L.A., D’Agostino, R.B., O’Donnell, C.J., Abdominal visceral and subcutaneous adipose tissue compartments: Association with metabolic risk factors in the framingham heart study. Circulation, 2007, 116, 39-48.

[2] Lavie, C.J., Milani, R. V., Ventura, H.O., Obesity and Cardiovascular Disease. Risk Factor, Paradox, and Impact of Weight Loss. J. Am. Coll. Cardiol., 2009, 53, 1925-1932.

[3] Kremers, S., Reubsaet, A., Martens, M., Gerards, S., Jonkers, R., Candel, M., De Weerdt, I., De Vries, N., Systematic prevention of overweight and obesity in adults: A qualitative and quantitative literature analysis. Obes. Rev., 2010, 11, 371-379.

[4] Zimmet, P., Alberti, K.G.M.M., Surgery or Medical Therapy for Obese Patients with Type 2 Diabetes? N. Engl. J. Med., 2012, $1635-1636$.

[5] Ooba, N., Kubota, K., Phenylpropanolamine and the risk of hemorrhagic stroke. Japanese J. Clin. Pharmacol. Ther., 2009, 40, $17-21$.

[6] Haller, C.A., Benowitz, N.L., Adverse cardiovascular and central nervous system events associated with dietary supplements containing ephedra alkaloids., 2000.

[7] Birari, R., Javia, V., Bhutani, K.K., Antiobesity and lipid lowering effects of Murraya koenigii (L.) Spreng leaves extracts and mahanimbine on high fat diet induced obese rats. Fitoterapia, 2010, 81, 1129-1133.

[8] Moyer, V.A., Force, U.S.P.S.T., Screening for and management of obesity in adults: U.S. Preventive Services Task Force recommendation statement. Ann Intern Med, 2012, 157, 373-378.

[9] Wu, J., Boström, P., Sparks, L.M., Ye, L., Choi, J.H., Giang, A.H., Khandekar, M., Virtanen, K.A., Nuutila, P., Schaart, G., Huang, K., Tu, H., Van Marken Lichtenbelt, W.D., Hoeks, J., Enerbäck, S., Schrauwen, P., Spiegelman, B.M., Beige adipocytes are a distinct type of thermogenic fat cell in mouse and human. Cell, 2012, 150, 366-376.

[10] Rosen, E.D., MacDougald, O.A., Adipocyte differentiation from the inside out. Nat. Rev. Mol. Cell Biol., 2006, 7, 885-896.

[11] Geloen, A., Roy, P.E., Bukowiecki, L.J., Regression of white adipose tissue in diabetic rats. Am. J. Physiol. - Endocrinol. Metab., 1989, 257, E547-E553.

[12] Barbatelli, G., Murano, I., Madsen, L., Hao, Q., Jimenez, M., Kristiansen, K., Giacobino, J.P., De Matteis, R., Cinti, S., The emergence of cold-induced brown adipocytes in mouse white fat depots is determined predominantly by white to brown adipocyte transdifferentiation. Am. J. Physiol. Endocrinol. Metab., 2010, 298, E1244-E1253.

[13] Farmer, S.R., Molecular determinants of brown adipocyte formation and function. Genes Dev., 2008, 22, 1269-1275.

\section{ACKNOWLEDGEMENTS}

This study was funded by the Project MARBIOTECH (reference NORTE-07-0124-FEDER-000047) within the SR\&TD Integrated Program MARVALOR - Building research and innovation capacity for improved management and valorization of marine resources, supported by ON.2 Program and by the European Regional Development Fund (ERDF) through COMPETE - Operational Competitiveness Programme and NOVOMAR (reference 0687-NOVOMAR1-P), and national funds through FCT - Foundation for Science and Technology, through the project UID/Multi/04423/2013. Ralph Urbatzka was supported by grant SFRH/BPD/112287/2015 (FCT).

[14] Ishibashi, J., Seale, P., Medicine. Beige can be slimming. Science, 2010, 328, 1113-1114.

[15] Petrovic, N., Walden, T.B., Shabalina, I.G., Timmons, J.A., Cannon, B., Nedergaard, J., Chronic peroxisome proliferatoractivated receptor $\gamma(\mathrm{PPAR} \gamma)$ activation of epididymally derived white adipocyte cultures reveals a population of thermogenically competent, UCP1-containing adipocytes molecularly distinct from classic brown adipocytes. J. Biol. Chem., 2010, 285, 7153-7164.

[16] Bartness, T.J., Vaughan, C.H., Song, C.K., Sympathetic and sensory innervation of brown adipose tissue. Int. J. Obes. (Lond)., 2010, 34 Suppl 1, S36-S42.

[17] Himms-Hagen, J., Melnyk, A., Zingaretti, M.C., Ceresi, E., Barbatelli, G., Cinti, S., Multilocular fat cells in WAT of CL316243-treated rats derive directly from white adipocytes. Am. J. Physiol. Cell Physiol., 2000, 279, C670-C681.

[18] Almind, K., Manieri, M., Sivitz, W.I., Cinti, S., Kahn, C.R., Ectopic brown adipose tissue in muscle provides a mechanism for differences in risk of metabolic syndrome in mice. Proc Natl.Acad Sci U S.A., 2007, 104, 2366-2371.

[19] De Matteis, R., Zingaretti, M.C., Murano, I., Vitali, A., Frontini, A., Giannulis, I., Barbatelli, G., Marcucci, F., Bordicchia, M., Sarzani, R., Raviola, E., Cinti, S., In vivo physiological transdifferentiation of adult adipose cells. Stem Cells, 2009, 27, 2761-2768.

[20] Zhang, Y., Proenca, R., Maffei, M., Barone, M., Leopold, L., Friedman, J.M., Positional cloning of the mouse obese gene and its human homologue. Nature, 1994, 372, 425-432.

[21] Jéquier, E., Leptin signaling, adiposity, and energy balance. Ann. N. Y. Acad. Sci., 2002, 967, 379-388.

[22] Kadowaki, T., Yamauchi, T., Adiponectin and adiponectin receptors. Endocr. Rev., 2005, 26, 439-451.

[23] Steppan, C.M., Bailey, S.T., Bhat, S., Brown, E.J., Banerjee, R.R., Wright, C.M., Patel, H.R., Ahima, R.S., Lazar, M.A., The hormone resistin links obesity to diabetes. Nature, 2001, 409, 307-312.

[24] McTernan, P.G., Kusminski, C.M., Kumar, S., Resistin. Curr. Opin. Lipidol., 2006, 17, 170-175.

[25] Ogden, C.L., Carroll, M.D., Kit, B.K., Flegal, K.M., Prevalence of obesity and trends in body mass index among US children and adolescents, 1999-2010. JAMA, 2012, 307, 483-90.

vom Saal, F.S., Nagel, S.C., Coe, B.L., Angle, B.M., Taylor, J.A., The estrogenic endocrine disrupting chemical bisphenol A (BPA) and obesity. Mol. Cell. Endocrinol., 2012, 354, 74-84.

[27] Tang-Péronard, J.L., Andersen, H.R., Jensen, T.K., Heitmann, B.L., Endocrine-disrupting chemicals and obesity development in humans: A review. Obes. Rev., 2011, 12, 622-636.

[28] Ley, R.E., Turnbaugh, P.J., Klein, S., Gordon, J.I., Microbial 
ecology: human gut microbes associated with obesity. Nature, 2006, 444, 1022-1023.

[29] Stephens, J.M., The Fat Controller: Adipocyte Development. PLoS Biol., 2012, 10, 11-13.

[30] Blüher, M., Adipokines - removing road blocks to obesity and diabetes therapy. Mol. Metab., 2014, 3, 230-240.

[31] Yao, L., Herlea-Pana, O., Heuser-Baker, J., Chen, Y., BarlicDicen, J., Roles of the chemokine system in development of obesity, insulin resistance, and cardiovascular disease. J. Immunol. Res., 2014, 2014.

[32] Guilherme, A., Virbasius, J. V, Puri, V., Czech, M.P., Adipocyte dysfunctions linking obesity to insulin resistance and type 2 diabetes. Nat. Rev. Mol. Cell Biol., 2008, 9, 367-377.

[33] Finucane, O.M., Reynolds, C.M., McGillicuddy, F.C., Roche, H.M., Insights into the role of macrophage migration inhibitory factor in obesity and insulin resistance. Proc. Nutr. Soc., 2012, 71, 622-33.

[34] Wang, Z.Q., Ribnicky, D., Zhang, X.H., Zuberi, A., Raskin, I., Yu, Y., Cefalu, W.T., An extract of Artemisia dracunculus L. enhances insulin receptor signaling and modulates gene expression in skeletal muscle in KK-Ay mice. J. Nutr. Biochem., 2011, 22, 71-78.

[35] Kraus, R.M., Houmard, J. a, Kraus, W.E., Tanner, C.J., Pierce, J.R., Choi, M.D., Hickner, R.C., Obesity, insulin resistance, and skeletal muscle nitric oxide synthase. J. Appl. Physiol., 2012, 113, 758-65.

[36] Surmi, B.K., Hasty, A.H., Macrophage infiltration into adipose tissue: initiation, propagation and remodeling. Future Lipidol., 2008, 3, 545-556.

[37] Phieler, J., Chung, K.-J., Chatzigeorgiou, A., Klotzsche-von Ameln, A., Garcia-Martin, R., Sprott, D., Moisidou, M., Tzanavari, T., Ludwig, B., Baraban, E., Ehrhart-Bornstein, M., Bornstein, S.R., Mziaut, H., Solimena, M., Karalis, K.P., Economopoulou, M., Lambris, J.D., Chavakis, T., The complement anaphylatoxin C5a receptor contributes to obese adipose tissue inflammation and insulin resistance. J. Immunol., 2013, 191, 4367-74.

[38] Chatzigeorgiou, a., Kandaraki, E., Papavassiliou, a. G., Koutsilieris, M., Peripheral targets in obesity treatment: A comprehensive update. Obes. Rev., 2014, 487-503.

[39] Fusco, R., Galgani, M., Procaccini, C., Franco, R., Pirozzi, G., Fucci, L., Laccetti, P., Matarese, G., Cellular and molecular crosstalk between leptin receptor and estrogen receptor-\{alpha $\}$ in breast cancer: molecular basis for a novel therapeutic setting. Endocr. Relat. Cancer, 2010, 17, 373-382.

[40] D’Esposito, V., Passaretti, F., Hammarstedt, A., Liguoro, D., Terracciano, D., Molea, G., Canta, L., Miele, C., Smith, U., Beguinot, F., Formisano, P., Adipocyte-released insulin-like growth factor- 1 is regulated by glucose and fatty acids and controls breast cancer cell growth in vitro. Diabetologia, 2012, 55, 2811-2822.

[41] Martel, P., Fantino, M., Mesolimbic dopaminergic system activity as a function of food reward: a microdialysis study. Pharmacol. Biochem. Behav., 1996, 53, 221-226.

[42] Baptista, T., Body weight gain induced by antipsychotic drugs: mechanisms and management. Acta Psychiatr. Scand., 1999, 100, $3-16$

[43] Towell, A., Muscat, R., Willner, P., Behavioural microanalysis of the role of dopamine in amphetamine anorexia. Pharmacol. Biochem. Behav., 1988, 30, 641-648.

[44] Foltin, R.W., Fischman, M.W., Nautiyal, C., The effects of cocaine on food intake of baboons before, during, and after a period of repeated desipramine. Pharmacol. Biochem. Behav., 1990, 36, 869-874.
Hainer, V., Kabrnova, K., Aldhoon, B., Kunesova, M., Wagenknecht, M., Serotonin and norepinephrine reuptake inhibition and eating behavior, in: Annals of the New York Academy of Sciences, 2006, pp. 252-269.

Li, C.R., Potenza, M.N., Lee, D.E., Planeta, B., Gallezot, J., Labaree, D., Henry, S., Nabulsi, N., Sinha, R., Ding, Y., Carson, R.E., Neumeister, A., NeuroImage Decreased norepinephrine transporter availability in obesity: Positron Emission Tomography imaging with ( S , S ) - [ $11 \mathrm{C}$ ] O-methylreboxetine. Neuroimage, 2014, $86,306-310$

[48] Eisenhut, M., Inflammation-induced Desensitization of $\beta$ Receptors in Acute Lung Injury. Am. J. Respir. Crit. Care Med., 2012, 185, 894.

[49] Polak, J., Klimcakova, E., Moro, C., Viguerie, N., Berlan, M., Hejnova, J., Richterova, B., Kraus, I., Langin, D., Stich, V., Effect of aerobic training on plasma levels and subcutaneous abdominal adipose tissue gene expression of adiponectin, leptin, interleukin 6, and tumor necrosis factor?? in obese women. Metabolism., 2006, $55,1375-1381$.

[50] Esposito, K., Pontillo, A., Ciotola, M., Di Palo, C., Grella, E., Nicoletti, G., Giugliano, D., Weight loss reduces interleukin-18 levels in obese women. J. Clin. Endocrinol. Metab., 2002, 87, 3864-3866.

Bush, J.A., Kraemer, W.J., Mastro, A.M., Triplett-McBride, N.T., Volek, J.S., Putukian, M., Sebastianelli, W.J., Knuttgen, H.G., Exercise and recovery responses of adrenal medullary neurohormones to heavy resistance exercise., 1999.

Van Der Horst, D.J., Van Marrewijk, W.J.A., Vullings, H.G.B., Diederen, J.H.B., Metabolic neurohormones: Release, signal transduction and physiological responses of adipokinetic hormones in insects. Eur. J. Entomol., 1999, 96, 299-308.

arra-Fernandes, A., Vanparys, C., Vergauwen, L., Knapen, D. Jorens, P.G., Blust, R., Toxicogenomics in the 3T3-L1 Cell Line, a New Approach for Screening of Obesogenic Compounds. Toxicol. Sci., 2014, 140, 352-63.

Lin, C.-S., Xin, Z.-C., Deng, C.-H., Ning, H., Lin, G., Lue, T.F., Defining adipose tissue-derived stem cells in tissue and in culture. Histol. Histopathol., 2010, 25, 807-815.

Sarjeant, K., Stephens, J.M., Adipogenesis. Cold Spring Harb. Perspect. Biol., 2012, 4.

Green, H., Meuth, M., An established pre-adipose cell line and its differentiation in culture. Cell, 1974, 3, 127-133.

Mendes, V., Monteiro, R., Pestana, D., Teixeira, D., Calhau, C., Azevedo, I., Differentiation : Implication of Antiproliferative and Apoptotic Effects. J. Agric. Food Chem., 2008, 11631-11637.

Kim, G.W., Lin, J.E., Blomain, E.S., Waldman, S., New advances in models and strategies for developing anti-obesity drugs. Expert Opin. Drug Discov., 2013, 8, 655-71.

Hampp, C., Kang, E.M., Borders-Hemphill, V., Use of prescription antiobesity drugs in the United States. Pharmacotherapy, 2013, 33, 1299-1307.

Woloshin, S., Schwartz, L.M., The new weight-loss drugs, lorcaserin and phentermine-topiramate: slim pickings? JAMA Intern. Med., 2014, 174, 615-619.

Goldstein, D.J., Rampey, A.H.J., Enas, G.G., Potvin, J.H., Fludzinski, L.A., Levine, L.R., Fluoxetine: a randomized clinical trial in the treatment of obesity. Int. J. Obes. Relat. Metab. Disord., 1994, 18, 129-135. Combination therapy of zonisamide and bupropion for weight reduction in obese women: A preliminary, randomized, open-label study. J. Clin. Psychiatry, 2007, 68, 1226-1229.

[63] Donnelly, L.A., Doney, A.S.F., Hattersley, A.T., Morris, A.D., Pearson, E.R., The effect of obesity on glycaemic response to metformin or sulphonylureas in Type 2 diabetes. Diabet. Med., 2006, 23, 128-133.
Bays, H., Dujovne, C., Anti-obesity drug development. Expert Opin. Investig. Drugs, 2002, 11, 1189-1204. 
[64] Jones, M.C., Therapies for diabetes: Pramlintide and exenatide. Am. Fam. Physician, 2007, 75, 1831-1835.

[65] Edelman, S. V., Darsow, T., Frias, J.P., Pramlintide in the treatment of diabetes. Int. J. Clin. Pract., 2006, 60, 1647-1653.

[66] Ferrannini, E., Sodium-glucose transporter-2 inhibition as an antidiabetic therapy. Nephrol. Dial. Transplant., 2010, 25, 20412043.

[67] Jabbour, S., Whaley, J., Tirmenstein, M., Poucher, S., Reilly, T., Boulton, D., Saye, J., List, J., Parikh, S., Targeting Renal Glucose Reabsorption for the Treatment of Type 2 Diabetes Mellitus Using the SGLT2 Inhibitor Dapagliflozin. Postgrad. Med., 2012, 124, 62-73.

[68] Zhi, J., Melia, A.T., Guerciolini, R., Chung, J., Kinberg, J., Hauptman, J.B., Patel, I.H., Retrospective population-based analysis of the dose-response (fecal fat excretion) relationship of orlistat in normal and obese volunteers., 1994.

[69] Dietrich, M.O., Horvath, T.L., Limitations in anti-obesity drug development: the critical role of hunger-promoting neurons. Nat. Rev. Drug Discov., 2012, 11, 675-691.

[70] Ling, H., Lenz, T.L., Burns, T.L., Hilleman, D.E., Reducing the risk of obesity: Defining the role of weight loss drugs. Pharmacotherapy, 2013, 33, 1308-1321.

[71] Danforth, E.J., Failure of adipocyte differentiation causes type II diabetes mellitus? Nat. Genet., 2000, 26, 13 .

[72] Dubois, S.G., Heilbronn, L.K., Smith, S.R., Albu, J.B., Kelley, D.E., Ravussin, E., Decreased expression of adipogenic genes in obese subjects with type 2 diabetes. Obesity (Silver Spring)., 2006, 14, 1543-1552.

[73] Gustafson, B., Hammarstedt, A., Hedjazifar, S., Smith, U., Restricted adipogenesis in hypertrophic obesity: The role of WISP2, WNT, and BMP4. Diabetes, 2013, 62, 2997-3004.

[74] Bartelt, A., Heeren, J., Adipose tissue browning and metabolic health. Nat. Rev. Endocrinol., 2014, 10, 24-36.

[75] Gnad, T., Scheibler, S., von Kugelgen, I., Scheele, C., Kilic, A. Glode, A., Hoffmann, L.S., Reverte-Salisa, L., Horn, P., Mutlu, S., El-Tayeb, A., Kranz, M., Deuther-Conrad, W., Brust, P., Lidell, M.E., Betz, M.J., Enerback, S., Schrader, J., Yegutkin, G.G., et al., Adenosine activates brown adipose tissue and recruits beige adipocytes via A2A receptors. Nature, 2014, 516, 395-399.

[76] Bade, R., Chan, H.F., Reynisson, J., Characteristics of known drug space. Natural products, their derivatives and synthetic drugs. Eur. J. Med. Chem., 2010, 45, 5646-5652.

[77] Li, J.W.-H., Vederas, J.C., Drug discovery and natural products: end of an era or an endless frontier? Science, 2009, 325, 161-165.

[78] Butler, M.S., Robertson, A.A.B., Cooper, M.A., Natural product and natural product derived drugs in clinical trials. Nat. Prod. Rep., 2014, 31, 1612-1661.

[79] Newman, D.J., Cragg, G.M., Battershill, C.N., Therapeutic agents from the sea: biodiversity, chemo-evolutionary insight and advances to the end of Darwin's 200th year. Diving Hyperb. Med., 2009, 39, 216-225.

[80] Olivera, B.M., -Conotoxin MVIIA : From Marine Snail Venom to Analgesic Drug. Drugs from Sea, 2000, 74-85.

[81] Wright, A.E., Forleo, D.A., Gunawardana, G.P., Gunasekera, S.P., Koehn, F.E., McConnell, O.J., Antitumor tetrahydroisoquinoline alkaloids from the colonial ascidian Ecteinascidia turbinata. $J$. Org. Chem., 1990, 55, 4508-4512.

[82] Hirata, Y., Uemura, D., Halichondrins - antitumor polyether macrolides from a marine sponge. Pure Appl. Chem., 1986, 58, 701-710.

[83] Stathis, A., Younes, A., The new therapeutical scenario of Hodgkin lymphoma. Ann. Oncol., 2015.

[84] Ansell, S.M., Brentuximab vedotin. Blood, 2014, 124, 3197-3200.
Pettit, G.R., Kamano, Y., Herald, C.L., Tuinman, A.A., Boettner,
F.E., Kizu, H., Schmidt, J.M., Baczynskyj, L., Tomer, K.B., Bontems, R.J., The isolation and structure of a remarkable marine animal antineoplastic constituent: dolastatin 10. J. Am. Chem. Soc., 1987, 109, 6883-6885.

[86] Niedermeyer, T., Brönstrup, M., Natural product drug discovery from microalgae, in: Microalgal Biotechnology: Integration and Economy, 2012, pp. 169-200.

Smith, C.J., Morin, N.R., Bills, G.F., Dombrowski, A.W., Salituro, G.M., Smith, S.K., Zhao, A., MacNeil, D.J., Novel sesquiterpenoids from the fermentation of Xylaria persicaria are selective ligands for the NPY Y5 receptor. J. Org. Chem., 2002, 67, 5001-5004.

[88] Schaffhauser, A.O., Stricker-Krongrad, A., Brunner, L., Cumin, F., Gerald, C., Whitebread, S., Criscione, L., Hofbauer, K.G., Inhibition of food intake by neuropeptide Y Y5 receptor antisense oligodeoxynucleotides. Diabetes, 1997, 46, 1792-1798.

[89] Miyashita, K., Nishikawa, S., Beppu, F., Tsukui, T., Abe, M., Hosokawa, M., The allenic carotenoid fucoxanthin, a novel marine nutraceutical from brown seaweeds. J. Sci. Food Agric., 2011, 91, 1166-1174.

[90] Kobayashi, Y., Nakano, Y., Kizaki, M., Hoshikuma, K., Yokoo, Y., Kamiya, T., Capsaicin-like anti-obese activities of evodiamine from fruits of Evodia rutaecarpa, a vanilloid receptor agonist. Planta Med., 2001, 67, 628-633.

[91] Nukitrangsan, N., Okabe, T., Toda, T., Inafuku, M., Iwasaki, H., Oku, H., Effect of Peucedanum japonicum Thunb Extract on High-fat Diet-induced Obesity and Gene Expression in Mice. $J$. Oleo Sci., 2012, 61, 89-101.

[92] Szewczyk, J.R., Laudeman, C., CCK1R agonists: a promising target for the pharmacological treatment of obesity. Curr. Top. Med. Chem., 2003, 3, 837-854.

[93] Cudennec, B., Ravallec-plé, R., Courois, E., Fouchereau-peron, M., Peptides from fish and crustacean by-products hydrolysates stimulate cholecystokinin release in STC-1 cells. 2008, 111, 970 975.

[94] Flachs, A.P.P.J.J., Hal, F., Polyunsaturated fatty acids of marine origin upregulate mitochondrial biogenesis and induce $\beta$ oxidation in white fat. 2005, 2365-2375.

[95] Gammelmark, A., Madsen, T., Varming, K., LundbyeChristensen, S., Schmidt, E.B., Low-dose fish oil supplementation increases serum adiponectin without affecting inflammatory markers in overweight subjects. Nutr. Res., 2012, 32, 15-23.

[96] Lefils-Lacourtablaise, J., Socorro, M., Géloën, A., Daira, P., Debard, C., Loizon, E., Guichardant, M., Dominguez, Z., Vidal, H., Lagarde, M., Bernoud-Hubac, N., The Eicosapentaenoic Acid Metabolite 15-Deoxy- $\delta 12,14$-Prostaglandin J3 Increases Adiponectin Secretion by Adipocytes Partly via a PPAR $\gamma$ Dependent Mechanism. PLoS One, 2013, 8, 1-12.

[97] Rossmeisl, M., Medrikova, D., van Schothorst, E.M., Pavlisova, J., Kuda, O., Hensler, M., Bardova, K., Flachs, P., Stankova, B., Vecka, M., Tvrzicka, E., Zak, A., Keijer, J., Kopecky, J., Omega3 phospholipids from fish suppress hepatic steatosis by integrated inhibition of biosynthetic pathways in dietary obese mice. Biochim. Biophys. Acta, 2014, 1841, 267-278.

[98] Höper, A.C., Salma, W., Khalid, A.M., Hafstad, A.D., Sollie, S.J., Raa, J., Larsen, T.S., Aasum, E., Oil from the marine zooplankton Calanus finmarchicus improves the cardiometabolic phenotype of diet-induced obese mice. Br. J. Nutr., 2013, 1-8.

[99] Höper, A.C., Salma, W., Sollie, S.J., Hafstad, A.D., Lund, J. Khalid, A.M., Raa, J., Aasum, E., Larsen, T.S., Wax Esters from the Marine Copepod Calanus finmarchicus Reduce Diet-Induced Obesity and Obesity-Related Metabolic Disorders in Mice. $J$. Nutr., 2014, 144, 164-9.

[100] Kong, C., Kim, J., Kim, S., Anti-obesity effect of sulfated glucosamine by AMPK signal pathway in 3T3-L1 adipocytes. Food Chem. Toxicol., 2009, 47, 2401-2406.

[101] Zhang, W., Guo, Y.-W., Gu, Y., Secondary metabolites from the 
South China Sea invertebrates: chemistry and biological activity. Curr. Med. Chem., 2006, 13, 2041-2090.

[102] Zhang, Y., Li, Y., Guo, Y., Jiang, H., Shen, X., A sesquiterpene quinone, dysidine, from the sponge Dysidea villosa, activates the insulin pathway through inhibition of PTPases. Acta Pharmacol. Sin., 2009, 30, 333-345.

[103] Salim, A.A., Rae, J., Fontaine, F., Conte, M.M., Khalil, Z. Martin, S., Parton, R.G., Capon, R.J., Heterofibrins: inhibitors of lipid droplet formation from a deep-water southern Australian marine sponge, Spongia (Heterofibria) sp. Org. Biomol. Chem., 2010, 8, 3188-3194.

[104] Byun, M.R., Kim, A.R., Hwang, J.-H., Sung, M.K., Lee, Y.K., Hwang, B.S., Rho, J.-R., Hwang, E.S., Hong, J.-H., Phorbaketal A stimulates osteoblast differentiation through TAZ mediated Runx2 activation. FEBS Lett., 2012, 586, 1086-1092.

[105] Byun, M.R., Lee, C.H., Hwang, J.H., Kim, a. R., Moon, S.A., Sung, M.K., Roh, J.R., Hwang, E.S., Hong, J.H., Phorbaketal A inhibits adipogenic differentiation through the suppression of PPAR??-mediated gene transcription by TAZ. Eur. J. Pharmacol., 2013, 718, 181-187.

[106] Liang, L.-F., Wang, T., Cai, Y.-S., He, W.-F., Sun, P., Li, Y.-F., Huang, Q., Taglialatela-Scafati, O., Wang, H.-Y., Guo, Y.-W., Brominated polyunsaturated lipids from the Chinese sponge Xestospongia testudinaria as a new class of pancreatic lipase inhibitors. Eur. J. Med. Chem., 2014, 79, 290-297.

[107] Sepe, V., D’Amore, C., Ummarino, R., Renga, B., D’Auria, M.V., Novellino, E., Sinisi, A., Taglialatela-Scafati, O., Nakao, Y., Limongelli, V., Zampella, A., Fiorucci, S., Insights on pregnane$\mathrm{X}$-receptor modulation. Natural and semisynthetic steroids from Theonella marine sponges. Eur. J. Med. Chem., 2014, 73, 126134.

[108] Bharate, S.B., Yadav, R.R., Battula, S., Vishwakarma, R.A., Meridianins : Marine-Derived Potent Kinase Inhibitors. 2012, 114.

[109] Radwan, M.A.A., El-Sherbiny, M., Synthesis and antitumor activity of indolylpyrimidines: marine natural product meridianin D analogues. Bioorg. Med. Chem., 2007, 15, 1206-1211.

[110] Park, Y., Lee, T., Choi, J., Sukbong, V., Lee, J., Park, J., Jang, B. Biochemical and Biophysical Research Communications Inhibition of adipogenesis and leptin production in 3T3-L1 adipocytes by a derivative of meridianin C. Biochem. Biophys. Res. Commun., 2014, 452, 1078-1083.

[111] Feng, Y., Shao, Y., Chen, F., Monascus pigments. Appl. Microbiol. Biotechnol., 2012, 96, 1421-1440.

[112] Kim, J.H., Kim, Y.O., Jeun, J., Choi, D.-Y., Shin, C.S., L-Trp and L-Leu-OEt derivatives of the monascus pigment exert high antiobesity effects on mice. Biosci. Biotechnol. Biochem., 2010, 74, 304-308.

[113] Jou, P.-C., Ho, B.-Y., Hsu, Y.-W., Pan, T.-M., The effect of Monascus secondary polyketide metabolites, monascin and ankaflavin, on adipogenesis and lipolysis activity in 3T3-L1. $J$. Agric. Food Chem., 2010, 58, 12703-12709.

[114] Hwang, H.S., Kim, H.A., Lee, S.H., Anti-obesity and Antidiabetic Effects of Deep Sea Water on ob / ob Mice. 2009, 531-539.

[115] Othmer, D.F., Roels, O.A., Power, fresh water, and food from cold, deep sea water. Science, 1973, 182, 121-125.

[116] Fujita, D., [Deep ocean water]. Shokuhin Eiseigaku Zasshi., 2001, $42, \mathrm{~J} 340-2$

[117] Wang, L.C., Lung, T.Y., Kung, Y.H., Wang, J.J., Tsai, T.Y., Wei, B.L., Pan, T.M., Lee, C.L., Enhanced anti-obesity activities of red mold dioscorea when fermented using deep ocean water as the culture water. Mar. Drugs, 2013, 11, 3902-3925.

[118] Shimokawa, K., Yamada, K., Kita, M., Uemura, D., Convergent synthesis and in vivo inhibitory effect on fat accumulation of (-)ternatin, a highly N-methylated cyclic peptide. Bioorg. Med. Chem. Lett., 2007, 17, 4447-4449.
[119] Shimokawa, K., Iwase, Y., Yamada, K., Uemura, D., Synthesis and inhibitory effect on fat accumulation of (-)-ternatin derivatives modified in the beta-OH-D-Leu(7) moiety. Org. Biomol. Chem., 2008, 6, 58-60.

[120] Lee, J.-K., Jang, J.-H., Seo, G.-S., Lee, J.-S., Manufacture and Characteristics of Food Additives, Phellineus linteus Powdercontaining Anti-obesity Lipase Inhibitor. Korean J. Mycol., 2010, $38,54-56$.

[121] Nagao, K., Inoue, N., Inafuku, M., Shirouchi, B., Morooka, T., Nomura, S., Nagamori, N., Yanagita, T., Mukitake mushroom (Panellus serotinus) alleviates nonalcoholic fatty liver disease through the suppression of monocyte chemoattractant protein 1 production in db/db mice. J. Nutr. Biochem., 2010, 21, 418-423.

[122] Inafuku, M., Nagao, K., Nomura, S., Shirouchi, B., Inoue, N., Nagamori, N., Nakayama, H., Toda, T., Yanagita, T., Protective effects of fractional extracts from Panellus serotinus on nonalcoholic fatty liver disease in obese, diabetic $\mathrm{db} / \mathrm{db}$ mice. $\mathrm{Br} . J$. Nutr., 2012, 107, 639-646.

[123] Ma, X., Zhou, F., Chen, Y., Zhang, Y., Hou, L., Cao, X., Wang, C., A polysaccharide from Grifola frondosa relieves insulin resistance of HepG2 cell by Akt-GSK-3 pathway. Glycoconj. J., 2014, 31, 355-363.

[124] Shen, K.-P., Su, C.-H., Lu, T.-M., Lai, M.-N., Ng, L.-T., Effects of Grifola frondosa non-polar bioactive components on high-fat diet fed and streptozotocin-induced hyperglycemic mice. Pharm. Biol., 2015, 53, 705-709.

[125] Chang, C.-J., Lin, C.-S., Lu, C.-C., Martel, J., Ko, Y.-F., Ojcius, D.M., Tseng, S.-F., Wu, T.-R., Chen, Y.-Y.M., Young, J.D., Lai, H.-C., Ganoderma lucidum reduces obesity in mice by modulating the composition of the gut microbiota. Nat. Commun., 2015, 6 , 7489 .

[126] Miyata, M., Koyama, T., Kamitani, T., Toda, T., Yazawa, K., Anti-obesity effect on rodents of the traditional Japanese food, tororokombu, shaved Laminaria. Biosci. Biotechnol. Biochem., 2009, 73, 2326-2328.

[127] Jeon, S.M., Kim, H.J., Woo, M.N., Lee, M.K., Chul Shin, Y., Bok Park, Y., Choi, M.S., Fucoxanthin-rich seaweed extract suppresses body weight gain and improves lipid metabolism in high-fat-fed C57BL/6J mice. Biotechnol. J., 2010, 5, 961-969.

[128] Ikeuchi, M., Koyama, T., Takahashi, J., Yazawa, K., Effects of astaxanthin in obese mice fed a high-fat diet. Biosci. Biotechnol. Biochem., 2007, 71, 893-899.

Arunkumar, E., Bhuvaneswari, S., Anuradha, C.V., An intervention study in obese mice with astaxanthin, a marine carotenoid - effects on insulin signaling and pro-inflammatory cytokines. Food Funct., 2012, 120-126.

[130] Eom, S.H., Lee, M.S., Lee, E.W., Kim, Y.M., Kim, T.H., Pancreatic lipase inhibitory activity of phlorotannins isolated from Eisenia bicyclis. Phyther. Res., 2013, 27, 148-151.

[131] Kwon, T.-H., Wu, Y.-X., Kim, J.-S., Woo, J.-H., Park, K.T., Kwon, O.J., Seo, H.-J., Kim, T., Park, N.-H., 6,6'-Bieckol inhibits adipocyte differentiation through downregulation of adipogenesis and lipogenesis in 3T3-L1 cells. J. Sci. Food Agric., 2014, n/an/a.

[132] Jang, W.S., Choung, S.Y., Antiobesity effects of the ethanol extract of Laminaria japonica Areshoung in high-fat-diet-induced obese rat. Evidence-Based Complement. Altern. Med., 2013, 2013.

[133] Kong, C.S., Kim, J.A., Ahn, B.N., Vo, T.S., Yoon, N.Y., Kim, S.K., 1-(3',5'-dihydroxyphenoxy)-7-(2",4",6-trihydroxyphenoxy)2,4,9-trihydroxydibenz o-1,4-dioxin inhibits adipocyte differentiation of 3T3-L1 fibroblasts. Mar. Biotechnol., 2010, 12, 299-307.

[134] Kim, S.-K., Kong, C.-S., Anti-adipogenic effect of dioxinodehydroeckol via AMPK activation in 3T3-L1 adipocytes. Chem. Biol. Interact., 2010, 186, 24-9.

[135] Kim, H., Kong, C., Lee, J.I., Kim, H., Baek, S., Seo, Y., Evaluation of Inhibitory E ff ect of Phlorotannins from Ecklonia 
cava on Triglyceride Accumulation in Adipocyte. 2013.

[136] Jung, H.A., Jung, H.J., Jeong, H.Y., Kwon, H.J., Kim, M.S., Choi, J.S., Anti-adipogenic activity of the edible brown alga Ecklonia stolonifera and its constituent fucosterol in 3T3-L1 adipocytes. Arch. Pharm. Res., 2014, 37, 713-720.

[137] Kim, S.N., Choi, H.Y., Lee, W., Park, G.M., Shin, W.S., Kim, Y.K., Sargaquinoic acid and sargahydroquinoic acid from Sargassum yezoense stimulate adipocyte differentiation through PPAR $\alpha / \gamma$ activation in 3T3-L1 cells. FEBS Lett., 2008, 582, 3465-3472.

[138] Kim, J.-A., Karadeniz, F., Ahn, B.-N., Kwon, M.S., Mun, O.-J., Bae, M.J., Seo, Y., Kim, M., Lee, S.-H., Kim, Y.Y., Kong, C.-S., Bioactive quinone derivatives from marine brown algae Sargassum thunbergii induce anti-adipogenic and proosteoblastogenic activities. J. Sci. Food Agric., 2015, n/a-n/a.

[139] Chen, Z., Wang, T., Song, N., Yan, Q., Fang, Y., Guan, H., Liu, $\mathrm{H}$., Isolation of the Molecular Species of

Monogalactosyldiacylglycerols from Brown Edible Seaweed Sargassum horneri and Their Inhibitory E ff ects on Triglyceride Accumulation in 3T3-L1 Adipocytes. J. Agric. Food Chem., 2014, $62,11157-11162$.

[140] Kim, M.J., Chang, U.J., Lee, J.S., Inhibitory effects of fucoidan in 3T3-L1 adipocyte differentiation. Mar. Biotechnol., 2009, 11, 557-562.

[141] Patankar, M.S., Oehninger, S., Barnett, T., Williams, R.L., Clark, G.F., A revised structure for fucoidan may explain some of its biological activities. J. Biol. Chem., 1993, 268, 21770-21776.

[142] Park, M., Jung, U., Roh, C., Fucoidan from Marine Brown Algae Inhibits Lipid Accumulation. 2011, 1359-1367.

[143] Belhadj, S., Hentati, O., Elfeki, A., Hamden, K., Inhibitory activities of Ulva lactuca polysaccharides on digestive enzymes related to diabetes and obesity. Arch. Physiol. Biochem., 2013, $119,81-7$.

[144] Kumar, S., Magnusson, M., Ward, L., Paul, N., Brown, L., Seaweed Supplements Normalise Metabolic, Cardiovascular and Liver Responses in High-Carbohydrate, High-Fat Fed Rats. Mar. Drugs, 2015, 13, 788-805.

[145] Li, Z., Noda, K., Fujita, E., Manabe, Y., Hirata, T., Sugawara, T., The Green Algal Carotenoid Siphonaxanthin Inhibits Adipogenesis in 3T3-L1 Preadipocytes and the Accumulation of Lipids in White Adipose Tissue of KK-Ay Mice 1 - 3. 2015, 1-9.

[146] Pulz, O., Gross, W., Valuable products from biotechnology of microalgae. Appl. Microbiol. Biotechnol., 2004, 65, 635-648.

[147] Ku, C.S., Yang, Y., Park, Y., Lee, J., Health benefits of blue-green algae: prevention of cardiovascular disease and nonalcoholic fatty liver disease. J. Med. Food, 2013, 16, 103-11.

[148] Deng, R., Chow, T.-J., Hypolipidemic, antioxidant, and antiinflammatory activities of microalgae Spirulina. Cardiovasc. Ther., 2010, 28, e33-45.

[149] Miranda, M.S., Cintra, R.G., Barros, S.B., Mancini Filho, J. Antioxidant activity of the microalga Spirulina maxima. Braz. J. Med. Biol. Res., 1998, 31, 1075-1079.

[150] Iwata, K., Inayama, T., Kato, T., Effects of Spirulina platensis on plasma lipoprotein lipase activity in fructose-induced hyperlipidemic rats. J. Nutr. Sci. Vitaminol. (Tokyo)., 1990, 36, 165-171.

[151] Gonzalez de Rivera, C., Miranda-Zamora, R., Diaz-Zagoya, J.C., Juarez-Oropeza, M.A., Preventive effect of Spirulina maxima on the fatty liver induced by a fructose-rich diet in the rat, a preliminary report. Life Sci., 1993, 53, 57-61.

[152] Torres-Duran, P. V, Miranda-Zamora, R., Paredes-Carbajal, M.C., Mascher, D., Ble-Castillo, J., Diaz-Zagoya, J.C., Juarez-Oropeza, M.A., Studies on the preventive effect of Spirulina maxima on fatty liver development induced by carbon tetrachloride, in the rat. J. Ethnopharmacol., 1999, 64, 141-147.
G.B.K.S., Alleviation of metabolic abnormalities induced by excessive fructose administration in Wistar rats by Spirulina maxima. Indian J. Med. Res., 2012, 135, 422-428.

[154] Cheong, S.H., Kim, M.Y., Sok, D.-E., Hwang, S.-Y., Kim, J.H., Kim, H.R., Lee, J.H., Kim, Y.-B., Kim, M.R., Spirulina prevents atherosclerosis by reducing hypercholesterolemia in rabbits fed a high-cholesterol diet. J. Nutr. Sci. Vitaminol. (Tokyo)., 2010, 56, $34-40$.

[155] Fan, Y.Y., Chapkin, R.S., Importance of dietary gamma-linolenic acid in human health and nutrition. J. Nutr., 1998, 128, 14111414.

[156] Ou, Y., Lin, L., Yang, X., Pan, Q., Cheng, X., Antidiabetic potential of phycocyanin: effects on KKAy mice. Pharm. Biol., 2013, 51, 539-44

[157] de Jesus Raposo, M.F., de Morais, R.M.S.C., de Morais, A.M.M.B., Bioactivity and Applications of Sulphated Polysaccharides from Marine Microalgae. Mar. Drugs, 2013, 11, 233-252.

[158] Romay, C., Gonzalez, R., Ledon, N., Remirez, D., Rimbau, V., Cphycocyanin: a biliprotein with antioxidant, anti-inflammatory and neuroprotective effects. Curr. Protein Pept. Sci., 2003, 4, 207-216.

[159] Remirez, D., Fernandez, V., Tapia, G., Gonzalez, R., Videla, L.A., Influence of C-phycocyanin on hepatocellular parameters related to liver oxidative stress and Kupffer cell functioning. Inflamm. Res., 2002, 51, 351-356.

[160] Gonzalez, R., Rodriguez, S., Romay, C., Ancheta, O., Gonzalez, A., Armesto, J., Remirez, D., Merino, N., Anti-inflammatory activity of phycocyanin extract in acetic acid-induced colitis in rats. Pharmacol. Res., 1999, 39, 55-59.

[161] Farooq, S.M., Boppana, N.B., Devarajan, A., Sekaran, S.D. Shankar, E.M., Li, C., Gopal, K., Bakar, S.A., Karthik, H.S., Ebrahim, A.S., C-phycocyanin confers protection against oxalatemediated oxidative stress and mitochondrial dysfunctions in MDCK cells. PLoS One, 2014, 9, e93056.

[162] Rasmussen, H.E., Blobaum, K.R., Jesch, E.D., Ku, C.S., Park, Y.K., Lu, F., Carr, T.P., Lee, J.-Y., Hypocholesterolemic effect of Nostoc commune var. sphaeroides Kutzing, an edible blue-green alga. Eur. J. Nutr., 2009, 48, 387-394.

[163] Rasmussen, H.E., Blobaum, K.R., Park, Y.-K., Ehlers, S.J., Lu, F., Lee, J.-Y., Lipid extract of Nostoc commune var. sphaeroides Kutzing, a blue-green alga, inhibits the activation of sterol regulatory element binding proteins in HepG2 cells. J. Nutr., 2008, 138, 476-481.

[164] Park, Y.-K., Rasmussen, H.E., Ehlers, S.J., Blobaum, K.R., Lu, F., Schlegal, V.L., Carr, T.P., Lee, J.-Y., Repression of proinflammatory gene expression by lipid extract of Nostoc commune var sphaeroides Kützing, a blue-green alga, via inhibition of nuclear factor-kappaB in RAW 264.7 macrophages. Nutr. Res., 2008, 28, 83-91.

[165] Yang, Y., Park, Y., Cassada, D.A., Snow, D.D., Rogers, D.G., Lee, J., In vitro and in vivo safety assessment of edible blue-green algae, Nostoc commune var. sphaeroides Kutzing and Spirulina plantensis. Food Chem. Toxicol., 2011, 49, 1560-1564.

[166] Amin, K.A., Nagy, M.A., Effect of Carnitine and herbal mixture extract on obesity induced by high fat diet in rats. Diabetol. Metab. Syndr., 2009, 14, 1-14.

[167] Kim, J.H., Kang, S.A., Han, S.-M., Shim, I., Comparison of the antiobesity effects of the protopanaxadiol- and protopanaxatrioltype saponins of red ginseng. Phytother. Res., 2009, 23, 78-85.

[168] Kim, S.J., Lee, Y.H., Han, M.D., Mar, W., Kim, W.K., Nam, K.W., Resveratrol, purified from the stem of Vitis coignetiae Pulliat, inhibits food intake in C57BL/6J Mice. Arch. Pharm. Res., 2010, 33, 775-780.

[169] Jones, K.S., Alimov, A.P., Rilo, H.L., Jandacek, R.J., Woollett, L. a, Penberthy, W.T., A high throughput live transparent animal bioassay to identify non-toxic small molecules or genes that 
regulate vertebrate fat metabolism for obesity drug development. Nutr. Metab. (Lond)., 2008, 5, 23.

[170] Kumar, S., Alagawadi, K.R., Anti-obesity effects of galangin, a pancreatic lipase inhibitor in cafeteria diet fed female rats. Pharm. Biol., 2013, 51, 607-613.

[171] Rao, V.S., de Melo, C.L., Queiroz, M.G.R., Lemos, T.L.G., Menezes, D.B., Melo, T.S., Santos, F.A., Ursolic acid, a pentacyclic triterpene from Sambucus australis, prevents abdominal adiposity in mice fed a high-fat diet. J. Med. Food, 2011, 14, 1375-1382.

[172] Choi, H., Eo, H., Park, K., Jin, M., Park, E.J., Kim, S.H., Park, J.E., Kim, S., A water-soluble extract from Cucurbita moschata shows anti-obesity effects by controlling lipid metabolism in a high fat diet-induced obesity mouse model. Biochem. Biophys. Res. Commun., 2007, 359, 419-425.

[173] Lee, J., Kim, D., Choi, J., Choi, H., Ryu, J.H., Jeong, J., Park, E.J., Kim, S.H., Kim, S., Dehydrodiconiferyl alcohol isolated from Cucurbita moschata shows anti-adipogenic and antilipogenic effects in 3T3-L1 cells and primary mouse embryonic fibroblasts. J. Biol. Chem., 2012, 287, 8839-8851.

[174] Karadeniz, F., Kim, J., Ahn, B., Kim, M., Kong, C., Antiadipogenic and Pro-osteoblastogenic Activities of Spergularia marina Extract. 2014, 19, 187-193.

[175] Karadeniz, F., Kim, J., Ahn, B.-N., Kwon, M., Kong, C.-S., Effect of Salicornia herbacea on Osteoblastogenesis and Adipogenesis in Vitro. Mar. Drugs, 2014, 12, 5132-5147.

[176] Chang, H.P., Wang, M.L., Chan, M.H., Chiu, Y.S., Chen, Y.H., Antiobesity activities of indole-3-carbinol in high-fat-diet-induced obese mice. Nutrition, 2011, 27, 463-470.

[177] Lee, H., Kang, R., Yoon, Y., Shikonin inhibits fat accumulation in 3T3-L1 adipocytes. Phytother. Res., 2010, 24, 344-351.

[178] Martineau, L.C., Herve, J., Muhamad, A., Saleem, A., Harris, C.S., Arnason, J.T., Haddad, P.S., Anti-adipogenic activities of Alnus incana and Populus balsamifera bark extracts, part I: sites and mechanisms of action. Planta Med., 2010, 76, 1439-1446.

[179] Lee, O.H., Kwon, Y.I., Apostolidis, E., Shetty, K., Kim, Y.C., Rhodiola-induced inhibition of adipogenesis involves antioxidant enzyme response associated with pentose phosphate pathway. Phyther. Res., 2011, 25, 106-115.

[180] González-Castejón, M., García-Carrasco, B., Fernández-Dacosta, R., Dávalos, A., Rodriguez-Casado, A., Reduction of adipogenesis and lipid accumulation by taraxacum officinale (dandelion) extracts in 3T3L1 adipocytes: An in vitro study. Phyther. Res., 2014, 28, 745-752.

[181] Ekanem, A.P., Wang, M., Simon, J.E., Moreno, D.A., Antiobesity properties of two African plants (Afromomum meleguetta and Spilanthes acmella) by pancreatic lipase inhibition. Phyther. Res., 2007, 21, 1253-1255.

[182] Cho, A.S., Jeon, S.M., Kim, M.J., Yeo, J., Seo, K.I., Choi, M.S., Lee, M.K., Chlorogenic acid exhibits anti-obesity property and improves lipid metabolism in high-fat diet-induced-obese mice. Food Chem. Toxicol., 2010, 48, 937-943.

[183] Norazmir, M.N.J., Ayub, M.Y., Beneficial lipid-lowering effects of pink guava puree in high fat diet induced-obese rats. Malays. $J$ Nutr., 2010, 16, 171-185.

[184] Ou, T.-T., Hsu, M.-J., Chan, K.-C., Huang, C.-N., Ho, H.-H., Wang, C.-J., Mulberry extract inhibits oleic acid-induced lipid accumulation via reduction of lipogenesis and promotion of hepatic lipid clearance. J. Sci. Food Agric., 2011, 91, 2740-2748.

[185] Tsuduki, T., Kikuchi, I., Kimura, T., Nakagawa, K., Miyazawa, $\mathrm{T}$., Intake of mulberry 1-deoxynojirimycin prevents diet-induced obesity through increases in adiponectin in mice. Food Chem., 2013, 139, 16-23.

[186] Li, Y.-G., Ji, D.-F., Zhong, S., Lin, T.-B., Lv, Z.-Q., Hu, G.-Y., Wang, X., 1-deoxynojirimycin inhibits glucose absorption and accelerates glucose metabolism in streptozotocin-induced diabetic mice. Sci. Rep., 2013, 3, 1377.

[187] Park, K.S., Raspberry ketone increases both lipolysis and fatty acid oxidation in 3T3-L1 adipocytes. Planta Med., 2010, 76, 1654-1658.

[188] Hasegawa, N., Garcinia extract inhibits lipid droplet accumulation without affecting adipose conversion in 3T3-L1 cells. Phytother. Res., 2001, 15, 172-173.

[189] Moreno, D. a., Ilic, N., Poulev, A., Raskin, I., Effects of Arachis hypogaea nutshell extract on lipid metabolic enzymes and obesity parameters. Life Sci., 2006, 78, 2797-2803.

[190] Ahn, T., Yang, G., Lee, H., Kim, M., Choi, H., Park, K., Lee, S., Kook, Y., An, H., Molecular mechanisms underlying the antiobesity potential of prunetin , an $\mathrm{O}$-methylated isoflavone. Biochem. Pharmacol., 2013, 85, 1525-1533.

[191] Beattie, J.H., Nicol, F., Gordon, M.J., Reid, M.D., Cantlay, L., Horgan, G.W., Kwun, I.S., Ahn, J.Y., Ha, T.Y., Ginger phytochemicals mitigate the obesogenic effects of a high-fat diet in mice: A proteomic and biomarker network analysis. Mol. Nutr. Food Res., 2011, 55, 203-213.

[192] Kim, J., Jang, D.S., Kim, H., Kim, J.S., Anti-lipase and lipolytic activities of ursolic acid isolated from the roots of Actinidia arguta. Arch. Pharm. Res., 2009, 32, 983-987.

Weisberg, S.P., Leibel, R., Tortoriello, D. V, Dietary curcumin significantly improves obesity-associated inflammation and diabetes in mouse models of diabesity. Endocrinology, 2008, 149, 3549-3558.

[194] Kim, C.Y., Le, T.T., Chen, C., Cheng, J.-X., Kim, K.-H. Curcumin inhibits adipocyte differentiation through modulation of mitotic clonal expansion. J. Nutr. Biochem., 2011, 22, 910-920.

[195] Gong, Z., Huang, C., Sheng, X., Zhang, Y., Li, Q., Wang, M.-W., Peng, L., Zang, Y.Q., The Role of Tanshinone IIA in the Treatment of Obesity through Peroxisome Proliferator-Activated Receptor $\gamma$ Antagonism. Endocrinology, 2009, 150, 104-113.

[196] Kim, Y.S., Lee, Y.M., Kim, J.H., Kim, J.S., Polygonum cuspidatum inhibits pancreatic lipase activity and adipogenesis via attenuation of lipid accumulation. BMC Complement. Altern. Med., 2013, 13, 282.

[197] Park, M., Lee, J., Choi, J., Hong, Y., Bae, I., Lim, K., Park, Y., Ha, H., 18B-Glycyrrhetinic Acid Attenuates Anandamide-Induced Adiposity and High-Fat Diet Induced Obesity. Mol. Nutr. Food Res., 2014, 58, 1436-1446.

[198] Quan, H.-Y., Baek, N.I., Chung, S.H., Licochalcone A prevents adipocyte differentiation and lipogenesis via suppression of peroxisome proliferator-activated receptor gamma and sterol regulatory element-binding protein pathways. J. Agric. Food Chem., 2012, 60, 5112-5120.

[199] Ohnishi, R., Matsui-Yuasa, I., Deguchi, Y., Yaku, K., Tabuchi, M., Munakata, H., Akahoshi, Y., Kojima-Yuasa, A., 1'acetoxychavicol acetate inhibits adipogenesis in 3T3-L1 adipocytes and in high fat-fed rats. Am. J. Chin. Med., 2012, 40, 1189-1204.

[200] Neill, S.O., Gould, K.S., Kilmartin, P.A., Mitchell, K.A., Markham, K.R., Antioxidant activities of red versus green leaves in Elatostema rugosum. Plant, Cell Environ., 2002, 25, 539-547.

[201] Atangwho, I.J., Edet, E.E., Uti, D.E., Obi, A.U., Asmawi, M.Z., Ahmad, M., Biochemical and histological impact of Vernonia amygdalina supplemented diet in obese rats. Saudi J. Biol. Sci., 2012, 19, 385-392.

[202] Cao, Z.H., Gu, D.H., Lin, Q.Y., Xu, Z.Q., Huang, Q.C., Rao, H., Liu, E.W., Jia, J.J., Ge, C.R., Effect of pu-erh tea on body fat and lipid profiles in rats with diet-induced obesity. Phyther. Res., 2011, 25, 234-238.

[203] Okabe, T., Toda, T., Nukitrangsan, N., Inafuku, M., Iwasaki, H., Oku, H., Peucedanum japonicum Thunb inhibits high-fat diet induced obesity in mice. Phytother. Res., 2011, 25, 870-877. 
Jeong, A.L., Lee, S., Park, M., Choi, Y. a., Lim, J.S., Yang, Y., Herbal extract THI improves metabolic abnormality in mice fed a high-fat diet. Nutr. Res. Pract., 2011, 5, 198-204.

[205] Koyama, T., Miyata, M., Nishimura, T., Yazawa, K., Suppressive Effects by Leaves of the Dypsis lutescens Palm on Fat Accumulation in 3T3-L1 Cells and Fat Absorption in Mice. Biosci. Biotechnol. Biochem., 2012, 76, 189-192.

[206] Miyata, M., Koyama, T., Yazawa, K., Water extract of Houttuynia cordata Thunb. leaves exerts anti-obesity effects by inhibiting fatty acid and glycerol absorption. J. Nutr. Sci. Vitaminol. (Tokyo)., 2010, 56, 150-156.

[207] Martins, F., Noso, T.M., Porto, V.B., Curiel, A., Gambero, A. Bastos, D.H.M., Ribeiro, M.L., Carvalho, P.D.O., Maté tea inhibits in vitro pancreatic lipase activity and has hypolipidemic effect on high-fat diet-induced obese mice. Obesity (Silver Spring)., 2010, 18, 42-47.

[208] Nakayama, T., Suzuki, S., Kudo, H., Sassa, S., Nomura, M. Sakamoto, S., Effects of three Chinese herbal medicines on plasma and liver lipids in mice fed a high-fat diet. $J$. Ethnopharmacol., 2007, 109, 236-240.

[209] Wu, C.-H., Yang, M.-Y., Chan, K.-C., Chung, P.-J., Ou, T.-T., Wang, C.-J., Improvement in high-fat diet-induced obesity and body fat accumulation by a Nelumbo nucifera leaf flavonoid-rich extract in mice. J. Agric. Food Chem., 2010, 58, 7075-7081.

[210] You, J.S., Lee, Y.J., Kim, K.S., Kim, S.H., Chang, K.J., Antiobesity and hypolipidaemic effects of Nelumbo nucifera seed ethanol extract in human pre-adipocytes and rats fed a high-fat diet. J. Sci. Food Agric., 2014, 94, 568-575.

[211] Xie, W., Zhang, Y., Wang, N., Zhou, H., Du, L., Ma, X., Shi, X., Cai, G., Novel effects of macrostemonoside A, a compound from Allium macrostemon Bung, on hyperglycemia, hyperlipidemia, and visceral obesity in high-fat diet-fed C57BL/6 mice. Eur. J. Pharmacol., 2008, 599, 159-165.

[212] Ikeda, I., Hamamoto, R., Uzu, K., Imaizumi, K., Nagao, K., Yanagita, T., Suzuki, Y., Kobayashi, M., Kakuda, T., Dietary gallate esters of tea catechins reduce deposition of visceral fat hepatic triacylglycerol, and activities of hepatic enzymes related to fatty acid synthesis in rats. Biosci. Biotechnol. Biochem., 2005, 69, 1049-1053

[213] Lee, H., Bae, S., Yoon, Y., The anti-adipogenic effects of ()epigallocatechin gallate are dependent on the WNT/beta-catenin pathway. J. Nutr. Biochem., 2013, 24, 1232-1240.

[214] Ahmad, R.S., Butt, M.S., Sultan, M.T., Mushtaq, Z., Ahmad, S., Dewanjee, S., De Feo, V., Zia-Ul-Haq, M., Preventive role of green tea catechins from obesity and related disorders especially hypercholesterolemia and hyperglycemia. J. Transl. Med., 2015, 13,79 .
[215] Chen, S., Osaki, N., Shimotoyodome, A., Green tea catechins enhance norepinephrine-induced lipolysis via a protein kinase Adependent pathway in adipocytes. Biochem. Biophys. Res. Commun., 2015.

[216] Hu, C., Yuan, Y. V., Kitts, D.D., Antioxidant activities of the flaxseed lignan secoisolariciresinol diglucoside, its aglycone secoisolariciresinol and the mammalian lignans enterodiol and enterolactone in vitro. Food Chem. Toxicol., 2007, 45, 22192227.

[217] Hasiewicz-Derkacz, K., Kulma, A., Czuj, T., Prescha, A., Zuk, M., Grajzer, M., Lukaszewicz, M., Szopa, J., Natural phenolics greatly increase flax (Linum usitatissimum) oil stability. $B M C$ Biotechnol., 2015, 15, 62

[218] Cha, Y.S., Yang, J.A., Back, H.I., Kim, S.R., Kim, M.G., Jung, S.J., Song, W.O., Chae, S.W., Visceral fat and body weight are reduced in overweight adults by the supplementation of Doenjang, a fermented soybean paste. Nutr. Res. Pract., 2012, 6, 520-526.

[219] Baranowski, M., Enns, J., Blewett, H., Yakandawala, U., Zahradka, P., Taylor, C.G., Dietary flaxseed oil reduces adipocyte size, adipose monocyte chemoattractant protein-1 levels and Tcell infiltration in obese, insulin-resistant rats. Cytokine, 2012, 59, 382-391.

[220] Adewale, A., Olaide, O., Oluwatoyin, E., Anti-obesity and antihyperlipidaemic effect of Hunteria umbellata seed extract in experimental hyperlipidaemia. 2010, 130, 307-314.

[221] Choi, I., Kim, Y., Park, Y., Seog, H., Choi, H., Anti-obesity activities of fermented soygerm isoflavones by Bifidobacterium breve. Biofactors, 2007, 29, 105-112.

[222] Cha, Y.-S., Kim, S.-R., Yang, J.-A., Back, H.-I., Kim, M.-G., Jung, S.-J., Song, W.O., Chae, S.-W., Kochujang, fermented soybean-based red pepper paste, decreases visceral fat and improves blood lipid profiles in overweight adults. Nutr. Metab. (Lond)., 2013, 10, 24

[223] Handa, T., Yamaguchi, K., Sono, Y., Yazawa, K., Effects of fenugreek seed extract in obese mice fed a high-fat diet. Biosci. Biotechnol. Biochem., 2005, 69, 1186-1188.

[224] Kim, Y., Choi, Y., Lee, J., Park, Y., Downregulated Lipid Metabolism in Differentiated Murine Adipocytes by Procyanidins from Defatted Grape Seed Meal. Biosci. Biotechnol. Biochem. 2014, 77, 1420-1423.

[225] Pang, X., Zhao, J., Zhang, W., Zhuang, X., Wang, J., Xu, R., Xu, $\mathrm{Z}$., Qu, W., Antihypertensive effect of total flavones extracted from seed residues of Hippophae rhamnoides L. in sucrose-fed rats. J. Ethnopharmacol., 2008, 117, 325-331.

[226] Qi, S., Zhou, D., Lotus seed epicarp extract as potential antioxidant and anti-obesity additive in Chinese Cantonese Sausage. Meat Sci., 2013, 93, 257-262. 